\title{
Post-treated prostate cancer: normal findings and signs of local relapse on multiparametric magnetic resonance imaging
}

\author{
João Lopes Dias, ${ }^{1,5,6}$ Rita Lucas, ${ }^{2}$ João Magalhães Pina, ${ }^{3,6}$ Raquel João,, \\ Nuno Vasco Costa, ${ }^{1,6}$ Cecília Leal, ${ }^{4,6}$ Tiago Bilhim, ${ }^{1,6}$ Luís Campos Pinheiro, ${ }^{1,6}$ \\ Rui Mateus Marques ${ }^{1,6}$ \\ ${ }^{1}$ Department of Radiology, Hospital de S. José, Rua José António Serrano, 1150-199 Lisbon, Portugal \\ ${ }^{2}$ Department of Radiology, Hospital de Santo António dos Capuchos, Alameda de Santo António dos Capuchos, $1169-050$ Lisbon, Portugal \\ ${ }^{3}$ Department of Urology, Hospital de S. José, Rua José António Serrano, 1150-199 Lisbon, Portugal \\ ${ }^{4}$ Department of Radiology, Hospital de Santa Marta, Rua de Santa Marta, 1169-1024 Lisbon, Portugal \\ ${ }^{5}$ Rua Herculano Rodrigues, n15, 2esq, 2695-044 Lisbon, Portugal \\ ${ }^{6}$ Faculdade de Ciências Médicas, Nova Medica School, Lisbon, Portugal
}

\begin{abstract}
The use of multiparametric magnetic resonance imaging (mp-MRI) for prostate cancer has increased over recent years, mainly for detection, staging, and active surveillance. However, suspicion of recurrence in the set of biochemical failure is becoming a significant reason for clinicians to request mp-MRI. Radiologists should be able to recognize the normal post-treatment MRI findings. Fibrosis and atrophic remnant seminal vesicles after prostatectomy are often found and must be differentiated from local relapse. Moreover, brachytherapy, external beam radiotherapy, cryosurgery, and hormonal therapy tend to diffusely decrease the signal intensity of the peripheral zone on T2-weighted images (T2WI) due to the loss of water content, consequently mimicking tumor and hemorrhage. The combination of T2WI and functional studies like diffusionweighted imaging and dynamic contrast-enhanced improves the identification of local relapse. Tumor recurrence tends to restrict on diffusion images and avidly enhances after contrast administration either within or outside the gland. The authors provide a pictorial review of the normal findings and the signs of local tumor relapse after radical prostatectomy, external beam radiotherapy, brachytherapy, cryosurgery, and hormonal therapy.
\end{abstract}

Key words: Prostate cancer-Multiparametric resonance imaging-Recurrence

Correspondence to: João Lopes Dias; email: joaolopesdias85@gmail.com
Multiparametric magnetic resonance imaging (mp-MRI) has been used for detection, localization, and staging of prostate cancer $(\mathrm{PCa})$ over the last few years. It combines T1 and T2-weighted images (WI) with at least two functional techniques such as dynamic contrast-enhanced MR imaging (DCE-MRI), diffusion-weighted imaging (DWI), and MR spectroscopy (MRS) [1]. The role of mp-MRI on PCa has, however, been extended to cases of active surveillance, patients who refused biopsy, MRI-guided or MRI-Ultrasound fusion biopsy, posttreatment surveillance, and diagnosis of recurrence [1-4].

Radical prostatectomy (RP) and radiotherapy (RT), either by external beam radiotherapy (EBRT) or brachytherapy (BT), have curative intent in patients with localized PCa. Other alternative treatment options like cryosurgery and high-intensity focused ultrasound (HIFU) are minimally invasive procedures with reduced toxicity. However, they are not completely established yet [5].

This manuscript provides a pictorial review of the normal findings and signs of local tumor relapse after RP, EBRT, BT, cryosurgery, and hormonal therapy (HT).

\section{Imaging approach to biochemical failure}

Recurrence after curative intent treatment is not uncommon. Among patients undergoing RP or RT, 27\% to $53 \%$ develop biochemical failure (BF), which is defined as a rise in prostate-specific antigen (PSA) level, and $16 \%$ to $35 \%$ need second-line treatment. PSA level remains the basis of follow-up after curative treatment, 
but the definition of BF differs between RP and RT. After RP, it is defined by two consecutive PSA values of $>0.2 \mathrm{ng} / \mathrm{mL}$. After RT, with or without short-term hormonal manipulation, it is defined by a PSA increase $>2 \mathrm{ng} / \mathrm{mL}$ higher than the initial PSA nadir value. We should emphasize that PSA recurrence tends to precede clinical recurrence after RP or RT, in some cases by several years [5-10].

PSA is also a good marker for following the course of metastatic PCa, usually treated with HT. However, it must be stressed that some poorly differentiated tumors do not secrete PSA and laboratorial follow-up should not constitute an isolated parameter in these patients. Clinical progression, commonly with bone pain, should also be considered [7].

After identifying a BF, it should be defined whether the recurrence has developed at local or distant sites. Patients with local-only disease should be distinguished and guided toward salvage local treatments. These treatments are associated with considerable morbidity and should be avoided in patients with distant metastases, who have a lower chance of benefiting from them and should undergo systemic therapies [8].

In the assessment of distant metastases, bone scans for bone metastases and abdominopelvic computed tomography (CT) for lymph node disease are usually requested. Positron emission tomography with CT (PET/ CT) and diffusion-weighted whole-body MRI, both more sensitive than bone scan and targeted radiographs in the detection of bone metastases in patients with highrisk PCa, may also be used [11-18]. According to the European Society of Urogenital Radiology (ESUR) [1], an MRI protocol based on T1WI and short tau inversion recovery (STIR) sequences for axial and pelvic skeleton is also recommended for bone metastasis assessment.

In local recurrence assessment, transrectal ultrasound (TRUS) is neither sensitive nor specific in both post-RP and RT cases. Due to its high contrast resolution, MRI has been increasingly used in cases of suspicion of $\mathrm{PCa}$ local relapse after RP or RT [19]. Conventional morphological sequences may be untrustworthy and accuracy levels have increased with combined use of functional techniques, namely DCE-MRI and DWI [7].

\section{Radical prostatectomy}

Radical prostatectomy implies removal of the entire prostate gland and both seminal vesicles, along with some of the fat surrounding tissue, with the goal of getting negative margins. The procedure should be accompanied by extended pelvic lymphadenectomy in patients with intermediate- and high-risk PCa. In men with low-risk $\mathrm{PCa}$ and $<50 \%$ positive biopsy cores, both the need and the extent of lymphadenectomy remain controversial as the risk of lymph node involvement is low $[5,20]$.
Radical retropubic prostatectomy (RRP) and perineal prostatectomy are performed through open incisions. Minimally invasive laparoscopic radical prostatectomy (LRP) and robot-assisted laparoscopic prostatectomy (RALP) have been recently developed and are being increasingly used in many centers. RALP is apparently associated with less blood loss and transfusion need, when compared to RRP. Negligible differences regarding the remaining post-operative complications were found [21, 22].

According to the European Association of Urology (EAU) [5], RP is indicated in patients with low- and intermediate-risk localized PCa (cT1a-T2b and Gleason Score [GS] 2-7 and PSA $<20 \mathrm{ng} / \mathrm{mL}$ ) and life expectancy higher than 10 years. Some selected patients with low-volume, high-risk localized PCa (cT3a or GS $8-10$ or PSA $>20 \mathrm{ng} / \mathrm{mL}$ ) and very high-risk localized PCa (cT3b-T4 N0 or any T N1) may also undergo RP, but always in a multimodality setting. The goal of RP is to eradicate the disease, conserving continence and potency $[23,24]$.

Over the last decade, the diagnosis of PCa has been established in younger men, so the preservation of sexual function has gained greater importance. Nerve-sparing RP may be attempted in patients with low risk for extracapsular disease (T1c, GS $<7$ and PSA $<10 \mathrm{ng} /$ $\mathrm{mL}$ ). The recognition of neurovascular bundle involvement on initial staging MRI is crucial $[5,25,26]$.

A persistently elevated post-RP PSA level (6 weeks after) is usually related to residual tumor, either due to distant micrometastases or residual pelvic disease. Rarely, a stable and low PSA level may be caused by residual benign glands [8]. If PSA level increases promptly after surgery, distant metastases are more likely to be the cause. On the other hand, a later and slower rise probably indicates local disease recurrence. pT2-3a N0 tumors are more associated with local recurrence, particularly when margins are negative, while pT3b-4 and/or pN1 cancers are more likely to relapse at distant sites. GS in the prostatectomy specimen also has prognostic implications: when $<8$, local relapse is more probable; when $\geq 8$, systemic recurrence and cancerrelated death are more likely to happen [10, 27].

In the majority of centers, post-RP recurrent cancer is defined as two consecutive PSA values of $0.2 \mathrm{ng} / \mathrm{mL}$ or more, despite some authors considering a higher cut-off of $0.4 \mathrm{ng} / \mathrm{mL}[7,8,10,28]$. When a post-RP BF is recognized, salvage RT is generally performed without histological confirmation of local relapse, since TRUS is neither sensitive nor specific and a negative biopsy does not rule out a local recurrence $[7,8]$. MRI is very useful in cases of suspicion of PCa local relapse after RP [19]. Several studies have been published over the last few years reporting higher accuracy rates for the combined use of morphological and functional sequences comparing to morphological sequences alone. Cirillo et al. [29] 
showed that contrast-enhanced sequences improve diagnostic performance when added to T2WI. In another study, Sciarra et al. [30] reported a sensitivity of $87 \%$ and specificity of $94 \%$ for the combined use of MRS and DCE-MRI in the detection of local PCa recurrence in patients with BF after RP.

After RP, bladder neck and vesicourethral anastomosis (VUA) are expected to appear as a strongly hypointense ring on T2WI, which reflects scar and fibrotic tissue (Figs. 1, 2), usually without or only with slightly progressive enhancement on DCE images [8]. It is common to find a regular and circumferential enhancement of the urethral wall under the bladder neck (Fig. 2). Both high $\mathrm{b}$ values and the apparent diffusion coefficient (ADC) map demonstrate low signal intensity due to fibrosis. Bladder neck may appear dysmorphic in some cases.

RP implies removal of the seminal vesicles. At their site, T2WI typically shows linear hypointense fibrosis (Figs. 1, 2). If nodularity is found, functional techniques should be assessed to exclude recurrence (Figs. 3, 4). Absent or slight and late enhancement, as well as lack of restriction on DWI, is unsuspicious signs. Retained seminal vesicles may also preserve their high signal intensity and convoluted structure on T2WI [8].

Local relapse after RP commonly appears in the retrovesical space and at the VUA. On T2WI, it is usually seen as an interruption of the normal hypointense ring of the bladder neck and VUA by a tumor with higher signal intensity (Figs. 5, 6, 7, 8) [31]. On DCE images, recurrence typically presents as early enhancing nodules (Figs. 5, 6, 7, 8, 9, 10). Some authors like Casciani et al. [32] have reported the utility of time-signal intensity curves. However, this feature is not consensual in the set of recurrence suspicion. Recurrence may also be seen as bright foci on DWI at high b values (Figs. 6, 9, 10), but this evaluation may be hampered due to lack of anatomical references, which may, however, be overcome using T2WI-DWI fusion images. Bone recurrence usually demonstrates the same functional behavior, presenting as enhancing nodules on DCE images (Fig. 11) and restrictive lesions on DWI.

\section{External beam radiotherapy}

External beam radiotherapy (EBRT) remains a valid alternative to surgery for curative therapy. It is recommended for localized PCa (T1c-T2c N0 M0), even in young patients who reject surgical intervention. In highrisk patients with locally advanced PCa (T3-4 N0 M0), long-term androgen deprivation therapy (ADT) before and during RT is recommended and leads to increased overall survival. EBRT may also be used after RP in T3 N0 M0 tumors, improving biochemical and clinical disease-free survival. This combination is particularly effective in cases with post-surgical positive margins. In very high-risk prostate cancer (c-pN1 M0), RT alone is inadequate. These patients, if no severe comorbidity is found, should undergo EBRT and immediate long-term adjuvant hormonal treatment $[5,33]$.

The current definition of $\mathrm{BF}$ after radiation is a PSA rise of more than $2 \mathrm{ng} / \mathrm{mL}$ above the post-treatment nadir [10]. In contrast to post-RP local relapse, it is necessary to obtain histological confirmation of the local recurrence after radiation therapy, taking into account the high morbidity of salvage options [8].
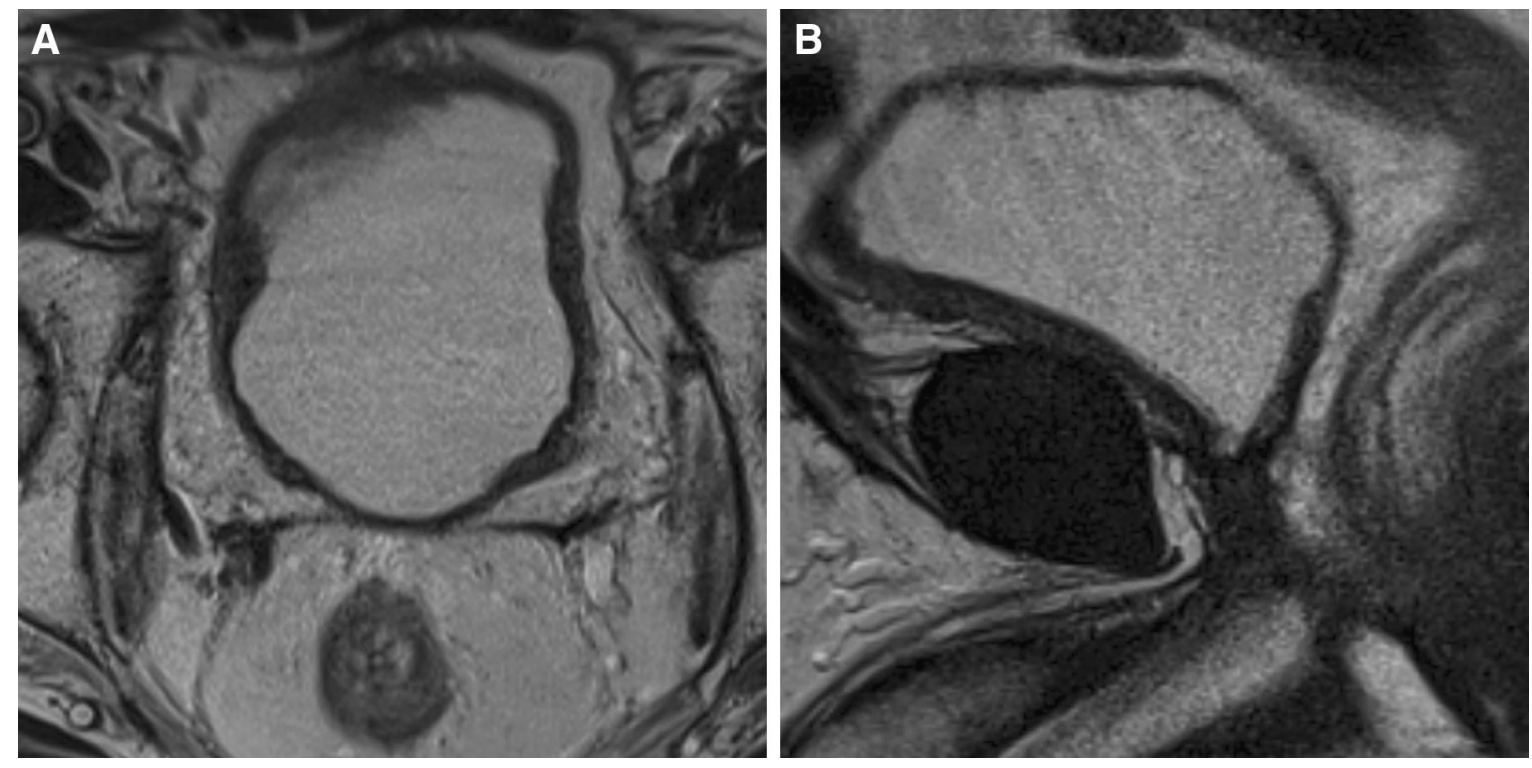

Fig. 1. Axial and sagittal T2 WI show normal post-prostatectomy fibrosis at the level of seminal vesicles (A) and typical hypointense bladder neck and peri-urethral tissue (B). 
After EBRT, the prostate gland loses normal zonal anatomy due to diffuse low signal intensity of the peripheral zone on T2WI (Figs. 12, 13, 14). This diminishes the contrast between tumor and irradiated tissue, hampering recurrence detection on morphological sequences [8].

Fibrosis and changes of parenchymal vascularization after RT modify the biological behavior of tumors and normal tissue, and may consequently limit the use of functional techniques like DCE-MRI or DWI. Even though, some manuscripts with promising results have been published. According to a study of Haider et al. [34], DCE-MRI performs better than T2WI in the detection of tumor relapse in the peripheral zone after EBRT. The authors reported sensitivity and specificity levels of $72 \%$ and $85 \%$, respectively. The enhancement of post-radiation fibrosis is low and slowly progressive, whereas recurrent cancer is typically hypervascular [8]. Kim et al. [35] concluded that the use of combined T2WI and DWI demonstrates better diagnostic performance when compared to T2WI alone for predicting locally recurrent $\mathrm{PCa}$ after radiation therapy. In another study, Morgan et al. [36] also emphasized the added vale of DWI, concluding that ADC measurement is useful for detecting local tumor relapse larger than $0.4 \mathrm{~cm}^{2}$ within the prostate. In a more recent study, Donati et al. [37]
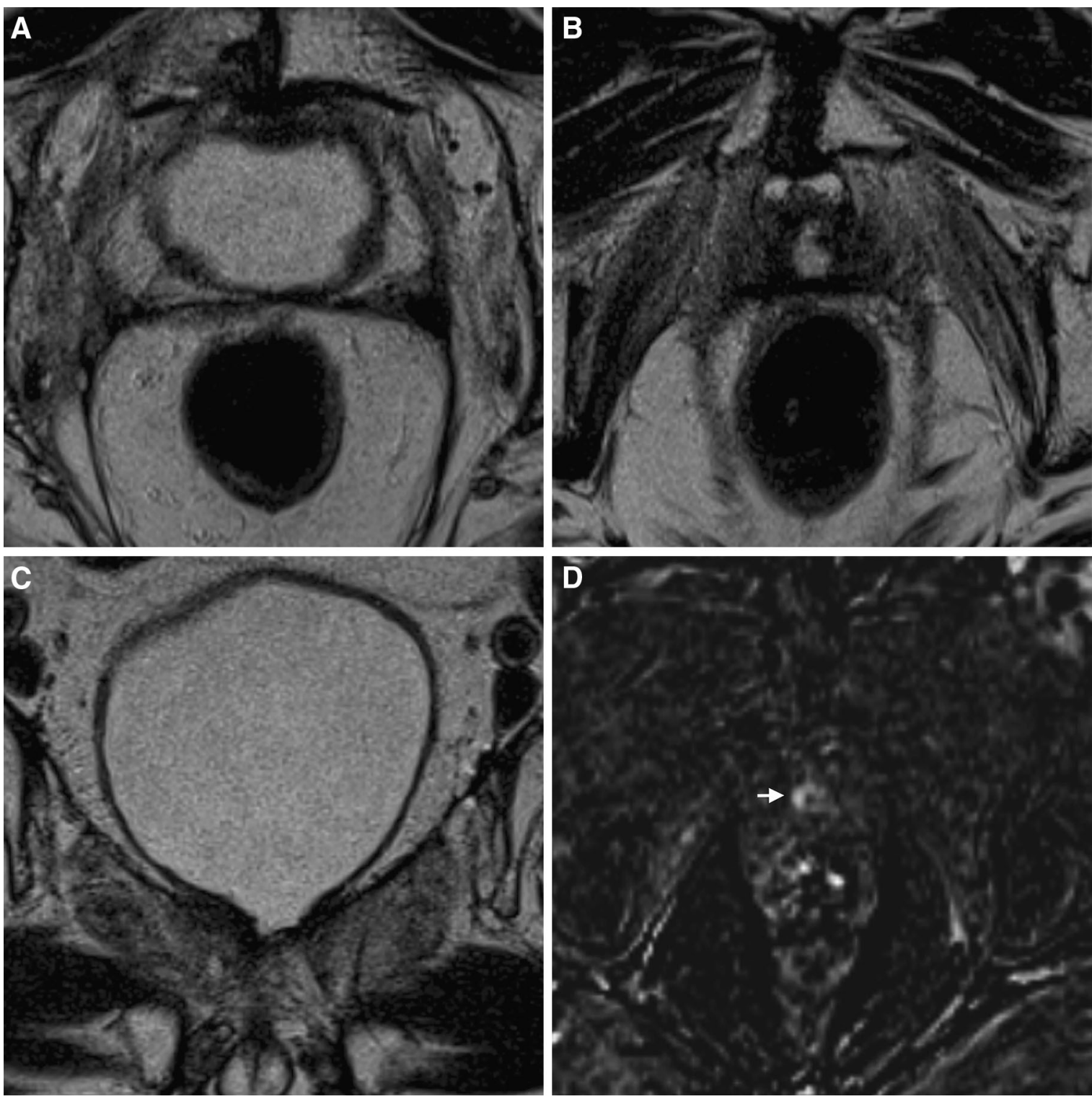

Fig. 2. Axial (A, B) and coronal (C) T2WI show normal postprostatectomy fibrosis at the level of seminal vesicles (A) and typical appearance of the bladder neck $(\mathbf{B}, \mathbf{C})$. It usually presents as a strongly hypointense ring with variable thick- ness. DCE subtracted image at a lower axial plane (D) shows the normal ring enhancement of the urethra (arrow), with no enhancement of the surrounding fibrotic tissue. 
concluded that the combination of T2WI and DWI achieves the best overall diagnostic accuracy and the highest inter-reader agreement in the detection of recurrent $\mathrm{PCa}$ after RT. In other studies, Arumainayagam et al. [38] and Akin et al. [39] demonstrated that mp-MRI using T2WI, DCE-MRI, and DWI is an accurate test for detecting radio-recurrent $\mathrm{PCa}$. The former achieved accuracy levels of $80 \%-90 \%$.

Some studies were also developed regarding the utility of MRS. Pucar et al. [40] showed that MRS might be more sensitive than TRUS and digital rectal examination for localization of post-EBRT cancer recurrence.

\section{Transperineal brachytherapy}

Transperineal BT is a secure and effective treatment for low-risk PCa. According to the EAU, it is recommended in patients with cT1-T2a N0 M0, GS $<7$ (or $3+4$ ), PSA $\leq 10 \mathrm{ng} / \mathrm{mL}, \leq 50 \%$ of biopsy cores involved with cancer, prostate volume $<50 \mathrm{~mL}$, without a previous transurethral resection of the prostate (TURP), and an International Prostatic Symptom Score $\leq 12$ [5, 21].

This transperineal technique is performed with TRUS. The patient is positioned in a dorsal decubitus gynecological position and seeds' implantation is performed under general anesthesia or spinal block [41].

There is no consensus on BF after BT. A PSA bounce, defined as a temporary increase of the PSA level followed by a further decrease, occurs in $30 \%-60 \%$ of patients 12-24 months after implantation, without clinical relevance. PSA bounce typically persists for about 12 months and PSA levels usually do not increase more than $1.0 \mathrm{ng} / \mathrm{mL}[8]$.
BT may produce several levels of magnetic susceptibility artifacts on both morphological and functional sequences (Fig. 15), hampering cancer detection. When visible, BT seeds appear as dark dots on T2WI and ADC map. Similarly to EBRT, post-BT prostate tends to appear diffusely hypointense on T2WI, with loss of the normal zonal anatomy (Fig. 16). BT seeds are often seen outside the gland, in the surrounding fat planes and less commonly at the base of the penis. According to Rouvière et al. [8], recurrent foci may be identified on DCE images as early-enhanced nodules. The use of DWI is not well established in the detection of intraglandular recurrence after BT mainly due to local artifacts, but it remains useful in the setting of locally aggressive relapse and bone metastases (Fig. 17, 18).

\section{Cryosurgery}

In cryosurgery, freezing of the prostate gland is guaranteed by the placement of cryoneedles under TRUS guidance, thermosensors at the level of the external sphincter and bladder neck, and insertion of a urethral warmer. A $-40^{\circ} \mathrm{C}$ temperature is achieved in the midgland and at the neurovascular bundle, generally after two freeze-thaw cycles, inducing cell death. Cellular dehydration, rupture of cellular membranes, vascular stasis, and microthrombi are the underlying mechanisms [42-45].

Potential candidates for cryosurgery are those with low- or intermediate-risk PCa and comorbidities that contraindicate RT or RP. At the time of therapy, prostate gland should be $<40 \mathrm{~mL}$, so prior hormonal downsize may be needed [43, 44].
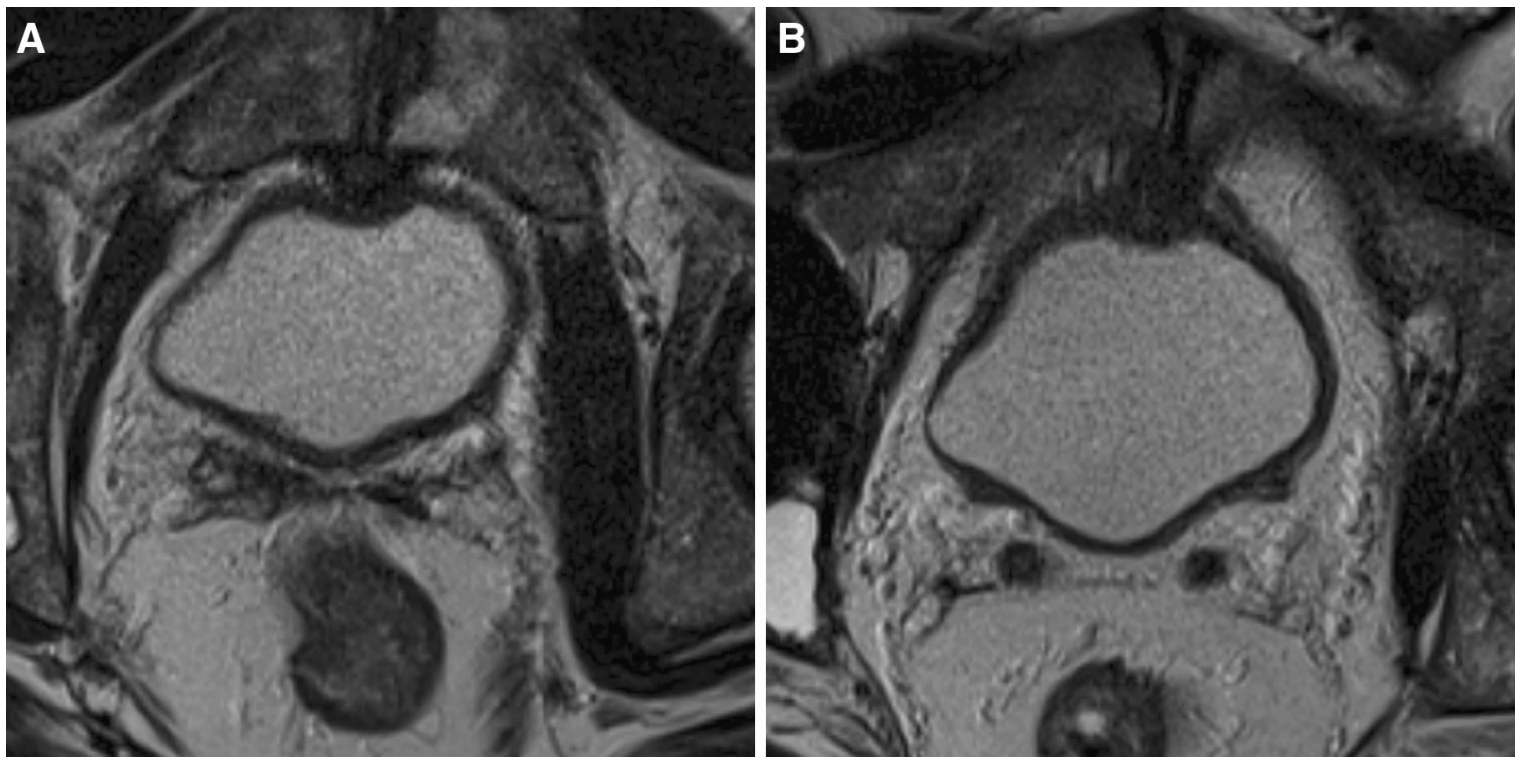

Fig. 3. Axial T2W images show normal post-prostatectomy fibrosis at the level of seminal vesicles and remnant right seminal vesicle $(\mathbf{A})$. The distal segment of the vas deferens may be also seen (B). 

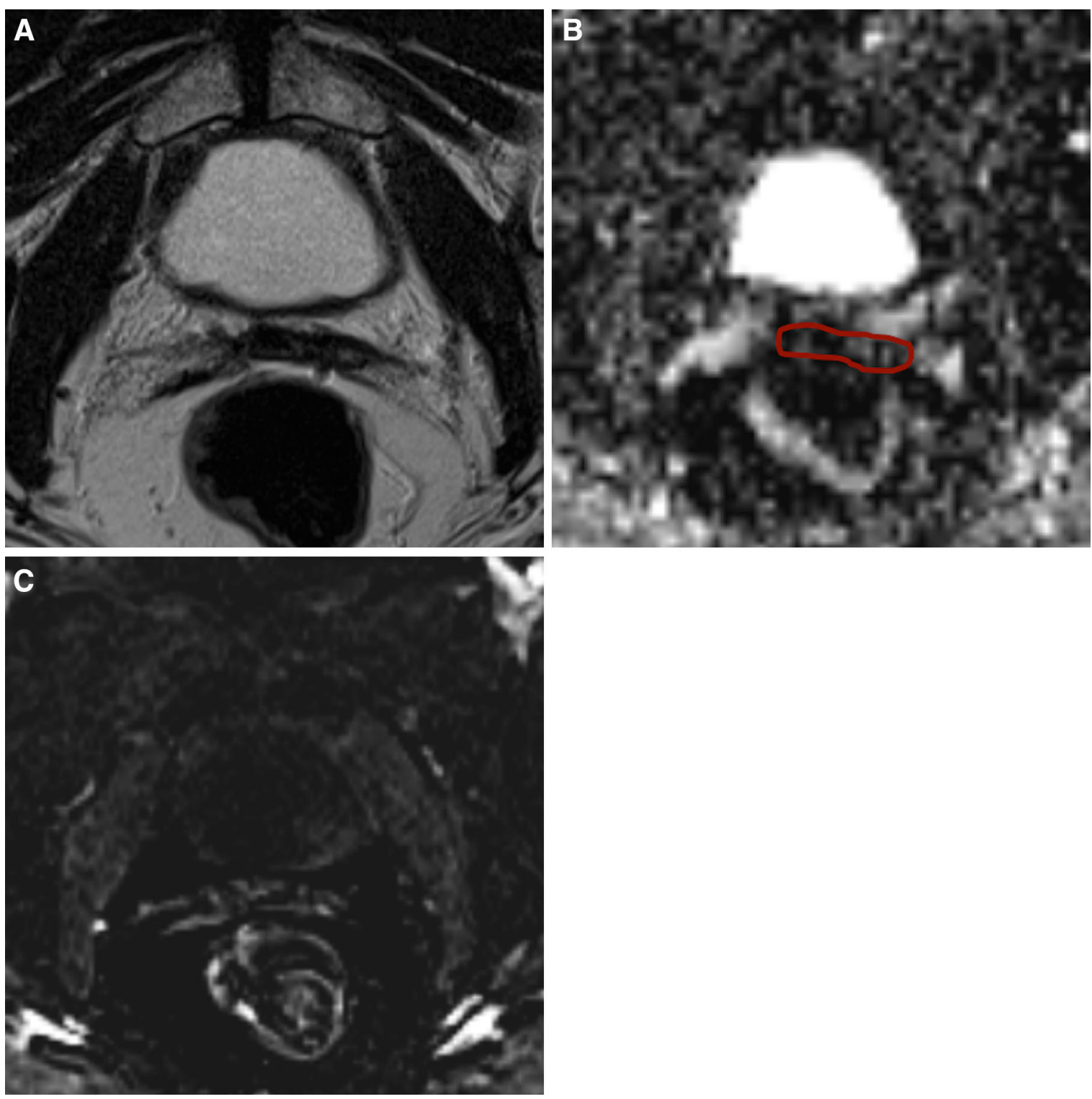

Fig. 4. Status post-RP in a patient with no laboratorial or imaging signs of recurrence. Axial T2WI A shows an elongated, strongly hypointese, thick fibrotic nodularity at the site of the left seminal vesicle. This area demonstrates very low

There are no validated criteria for BF after cryotherapy. Some centers consider a PSA cut-off of around $1 \mathrm{ng} / \mathrm{mL}$, which may be combined with a posttreatment biopsy [8, 42, 43].

Data in literature are scarce regarding both normal findings and PCa recurrence after cryosurgery. Similar to EBRT and BT, it is expected to find diffuse hyposignal within the peripheral zone on T2WI (Fig. 19). Some studies like that of Parivar et al. [46] concluded that MRS is superior to TRUS and MRI in detecting recurrence after cryosurgery. To the best of our knowledge, DCE-MRI and DWI have not been widely studied.

signal intensity on the ADC map (B, red contour) and at high $b$ values (not shown), as well as no significant enhancement on DCE images (C).

\section{Hormonal therapy}

Prostate cells undergo apoptosis when deprived of androgenic stimulation. Testosterone is crucial for growth and perpetuation of tumor cells, so androgen deprivation therapy (ADT) constitutes one of the therapeutic options for PCa. ADT aims to suppress the secretion of testicular androgens (castration) or inhibit the action of circulating androgens at the receptor level (anti-androgens) [10, 47].

Hormonal therapy (HT) is the standard option in metastatic $\mathrm{PCa}$, becoming mandatory if patients are 

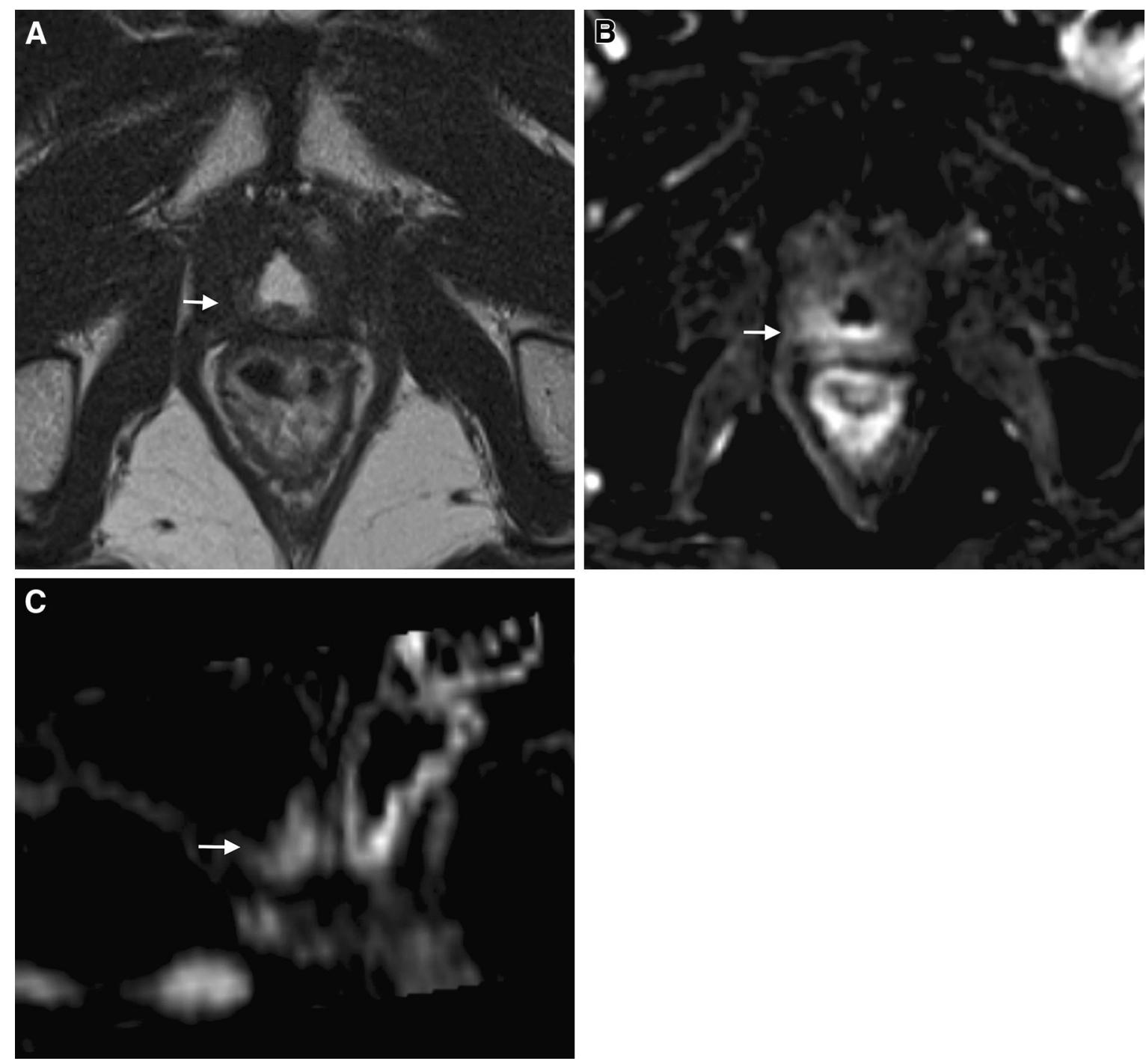

Fig. 5. Images in a 65-year-old man after RP. This patient had a PCa (GS 7 and initial PSA of $12.6 \mathrm{ng} / \mathrm{mL}$ ). BF was detected 6 years after RP (PSA $1.3 \mathrm{ng} / \mathrm{mL}$ ). Axial T2WI (A) shows interruption of the normal signal hypointensity of the

symptomatic. In $\mathrm{N}+\mathrm{M} 0$, HT also constitutes the standard treatment after extended node dissection if more than 2 positive nodes are found. Symptomatic patients with extensive T3-T4 and high PSA level ( $>25-50 \mathrm{ng} / \mathrm{mL}$ ) may also benefit with HT, but not as monotherapy, unless patients are unfit for RT. The use of HT in T1a-T2c localized PCa is limited and only indicated in symptomatic patients who need symptom palliation or are unfit for curative treatment [10].

Many patients undergoing HT were initially diagnosed with either metastatic or locally advanced cancer.

vesicourethral junction by a right posterior tumor with moderate signal intensity (arrow). This area demonstrates great enhancement on DCE images (subtracted axial image, B; sagittal reconstruction, $\mathbf{C}$ ).

In these cases, BF is frequently associated with fast symptomatic progression [48, 49]. Even under HT, it is common to find large tumors with extracapsular extension or invasion of the seminal vesicles on T2WI. Followup examinations may show changes in functional sequences, namely increasing ADC value and different dynamic post-gadolinium patterns. However, more studies are needed to validate these findings. HT may also decrease prostatic volume and hamper zonal anatomy depiction on T2WI by decreasing peripheral signal intensity, especially when combined with EBRT or BT (Fig. 20, 21). 

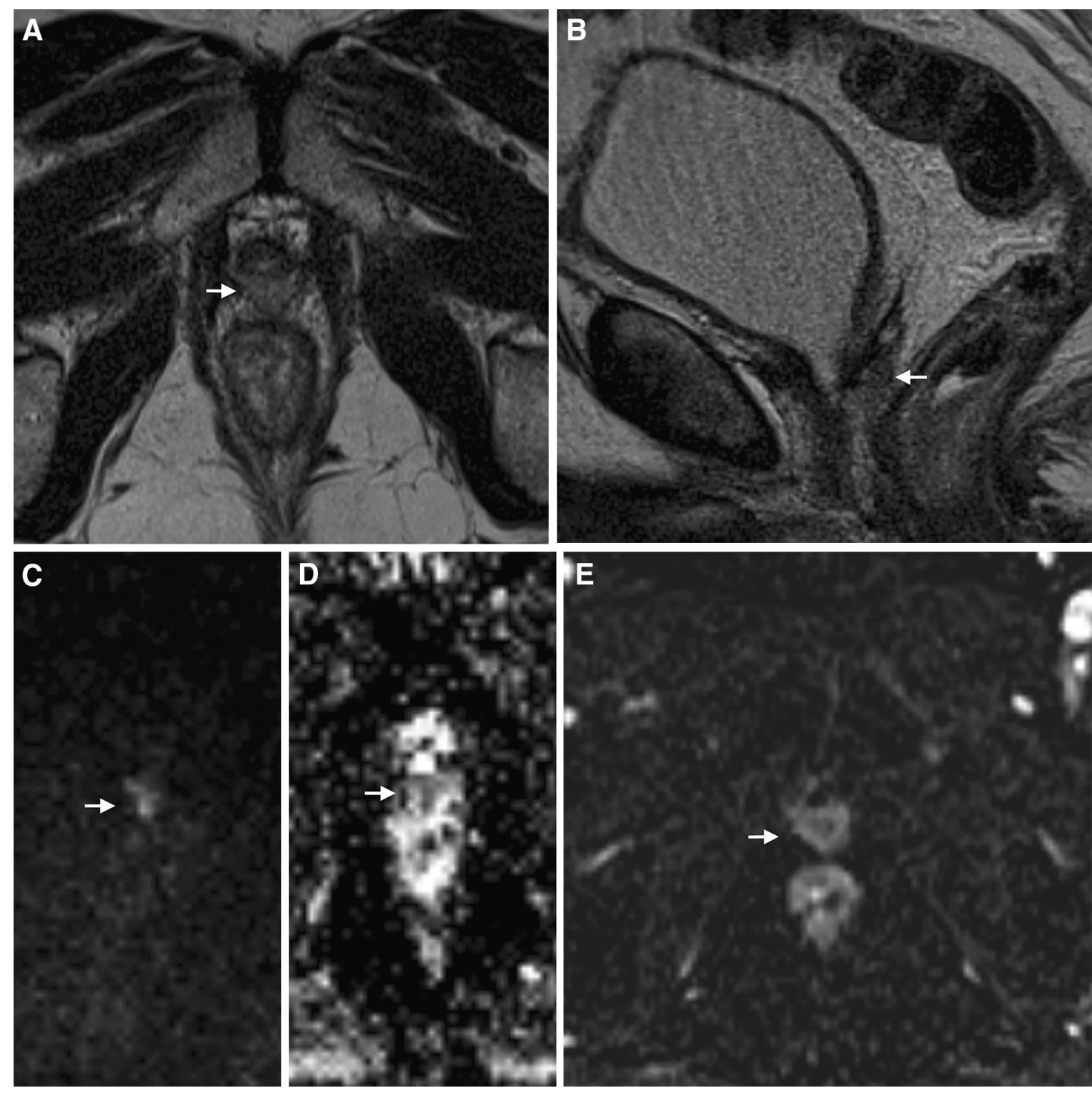

Fig. 6. Images in a 72-year-old man after $\mathrm{RP}$ due to $\mathrm{PCa}$ (GS 7). 4 years after surgery, BF was detected (PSA $16.2 \mathrm{ng} /$ located posteriorly to the vesicourethral junction (arrows). This nodule is bright on DWI at b 1200 (C), dark on the ADC $\mathrm{mL}$ ) and $\mathrm{HT}$ was initiated. Axial (A) and sagittal (B) T2WI map (D), and enhances on DCE images (E). 

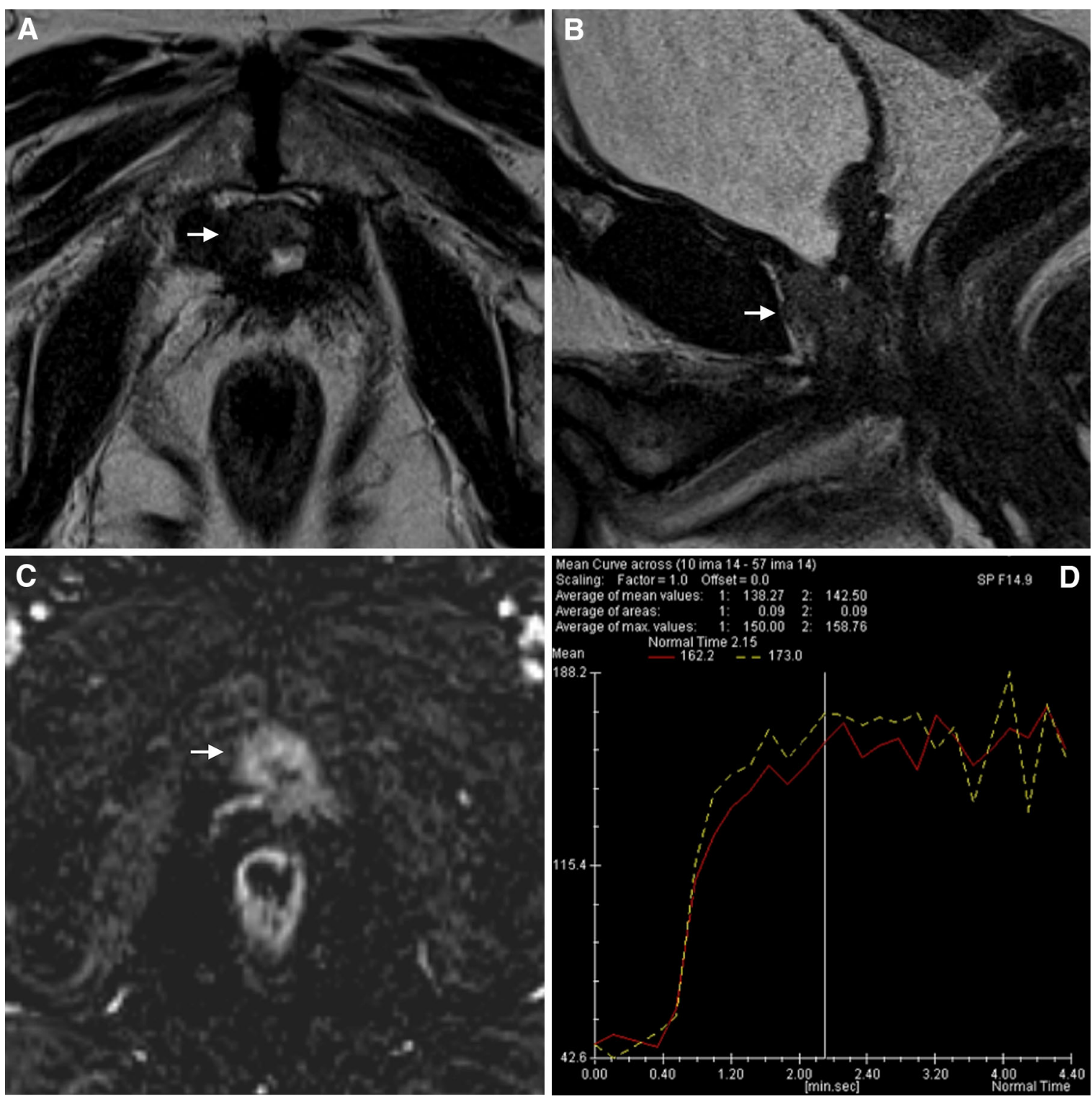

Fig. 7. Images in a 63-year-old man after RP. This patient had a PCa (GS 7, pT2c Nx, with negative margins). 10 years after surgery, BF was detected (PSA $9.8 \mathrm{ng} / \mathrm{mL}$ ). Axial (A) and sagittal (B) T2WI show interruption of the vesicourethral

junction hypointensity ring by an anterior, slightly hyperintense nodule (arrows). This nodule enhances on DCE images (C) and shows type 2 dynamic curve (D). 

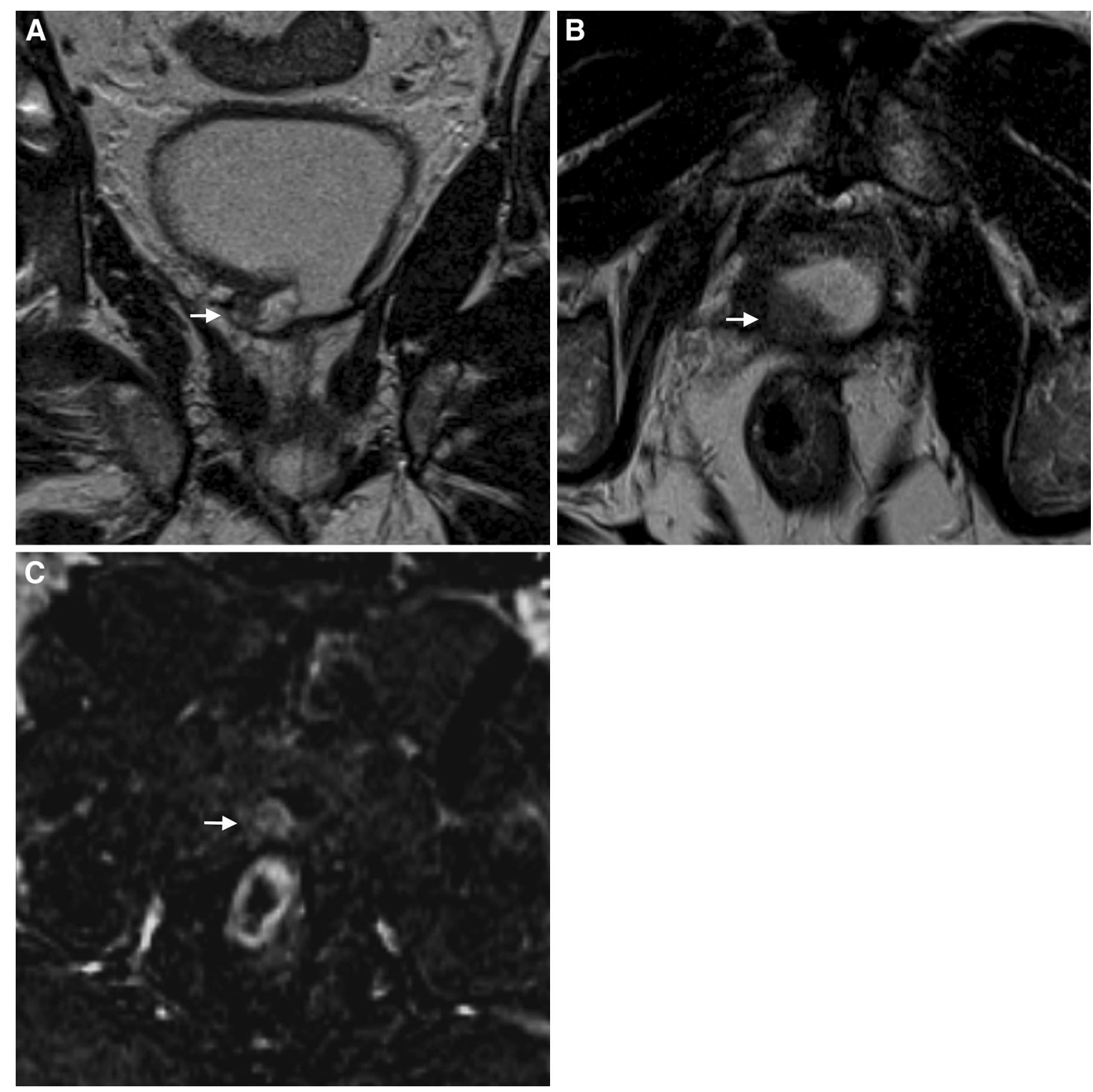

Fig. 8. Images in a 68-year-old man after $\mathrm{RP}$ due to $\mathrm{PCa}$ (GS 6). 15 years after surgery, BF was detected (PSA $0.80 \mathrm{ng} / \mathrm{mL}$ ). Coronal (A) and axial (B) T2WI show a dimorphic bladder neck and a poorly defined right posterior area with moderate signal intensity (arrows). Partial volume arti-

facts hamper morphologic evaluation, but DCE images (C) reveals suspicious enhancement. Posteriorly to the bladder neck, normal ring enhancement of the rectal mucosa is also seen. 

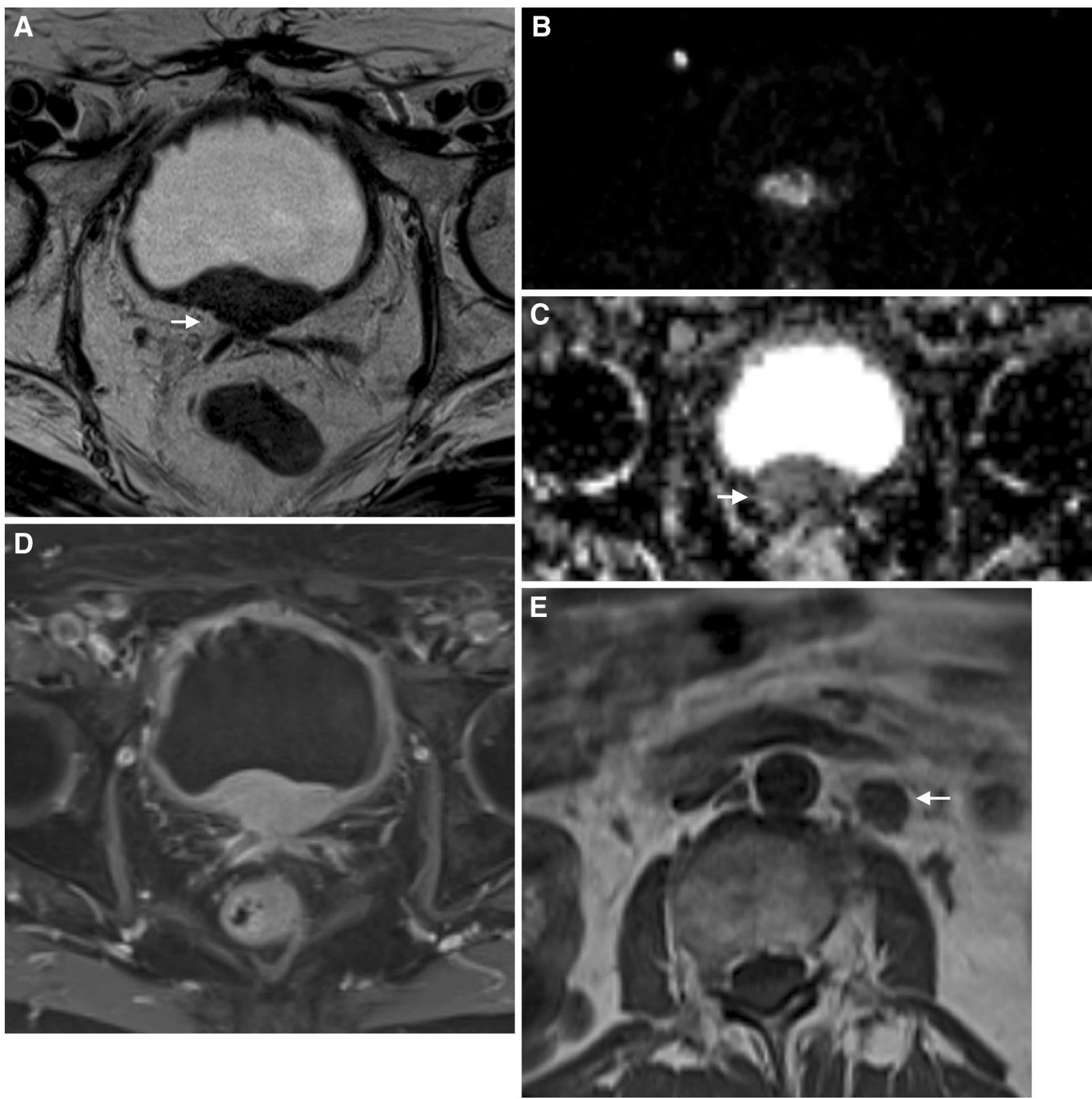

Fig. 9. Images in a 70-year-old man after RP and ilio-obtu-

highly restrictive on DWI (B), hypointense on the ADC map (C), and strongly enhancing on T1WI FS after gadolinium administration (D). A left lombo-aortic lymph node metastasis is also seen on $\mathrm{T} 1 \mathrm{WI}(\mathbf{E}$, arrow). detected under HT (PSA $6.4 \mathrm{ng} / \mathrm{mL}$ ). Axial T2WI (A) shows a nodular, hypointense thickening of the bladder base (arrow), 

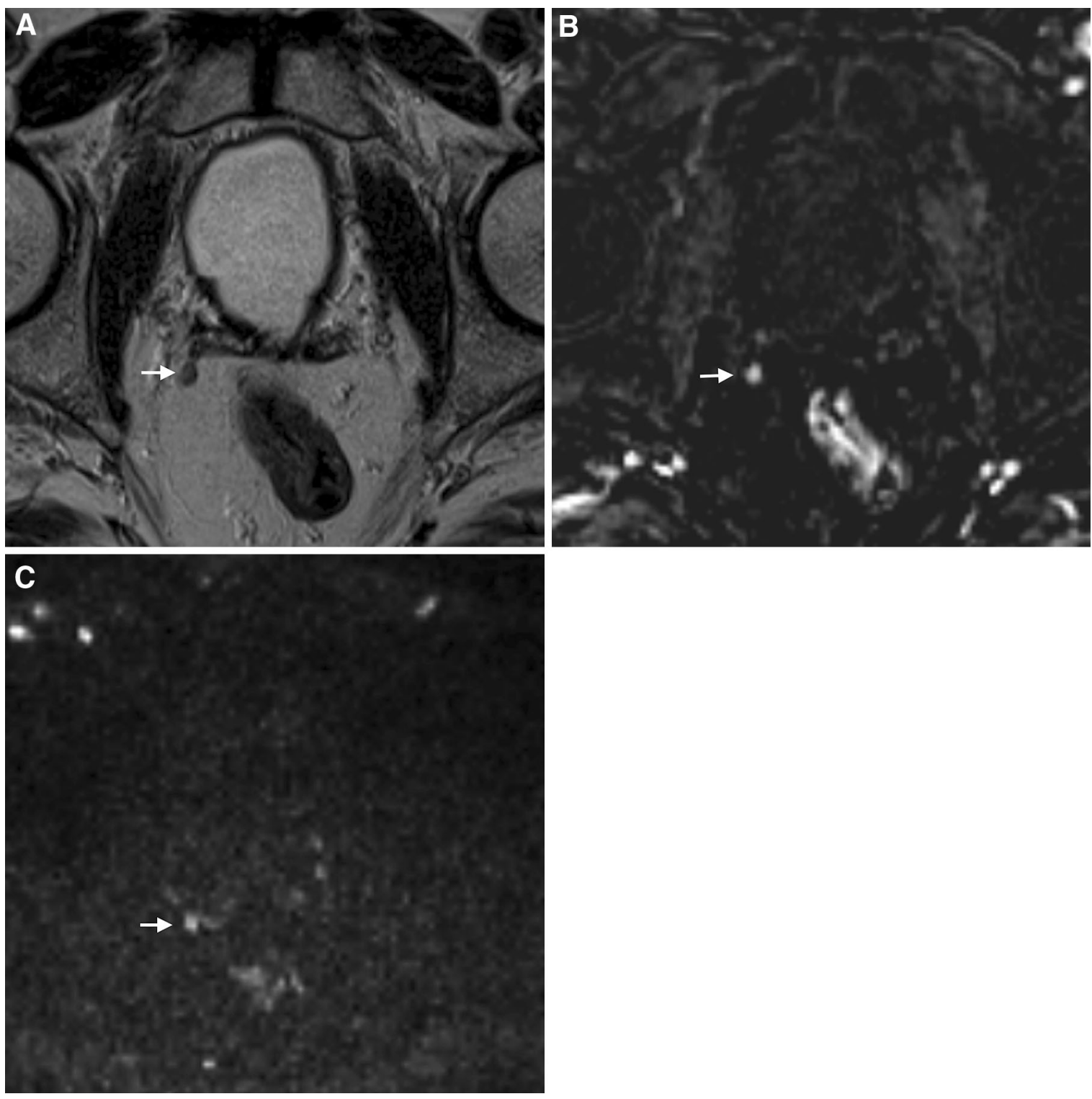

Fig. 10. Images in a 67-year-old man after $\mathrm{RP}$ due to $\mathrm{PCa}$ (GS 8). 5 years after surgery, BF was detected (PSA $0.90 \mathrm{ng} /$

mediate signal at the site of the right seminal vesicle. This $\mathrm{mL}$ ). Axial T2WI (A) shows a small tumor deposit with interrelapse focus enhances on DCE images (B) and demonstrates high signal intensity on DWI at b 1200 (C). 


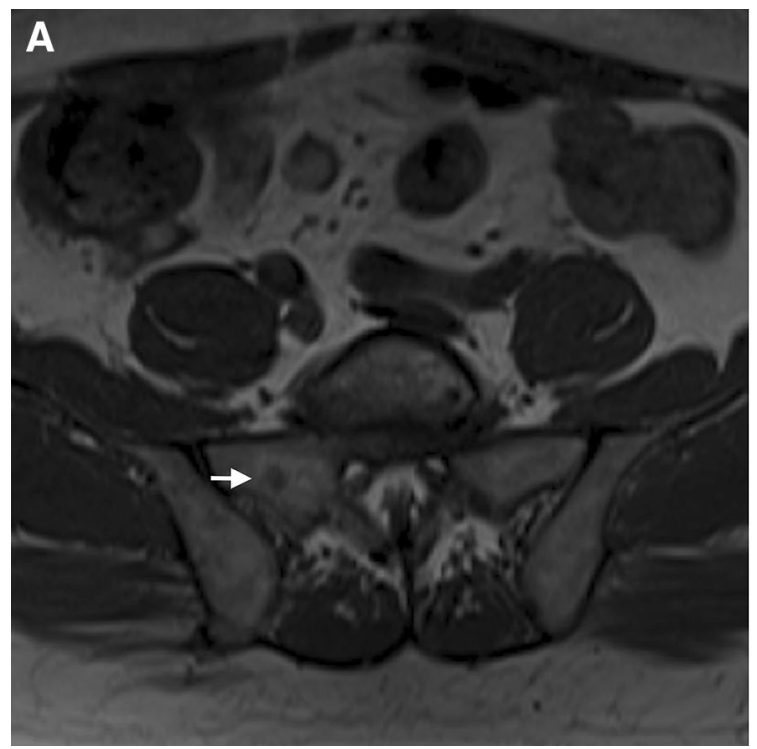

Fig. 11. Images in a 69-year-old man after RP. This patient had a PCa (GS 7). 6 years after surgery, BF was detected (PSA $1.90 \mathrm{ng} / \mathrm{mL}$ ). Axial T1WI (A) shows a small, hy-

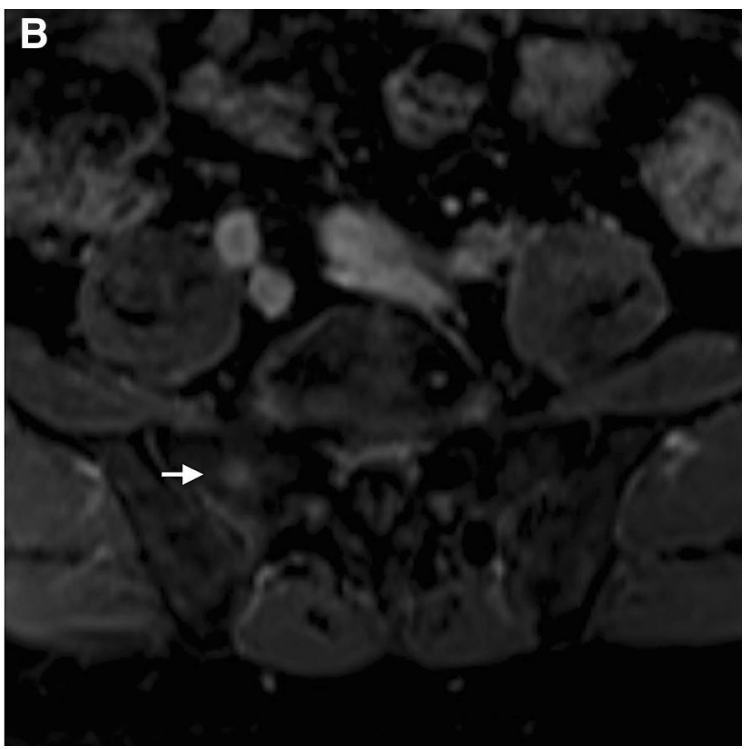

pointense bone metastasis in the right sacral wing. DCE image (B) shows early enhancement. No local relapse was found in the prostatectomy bed. 

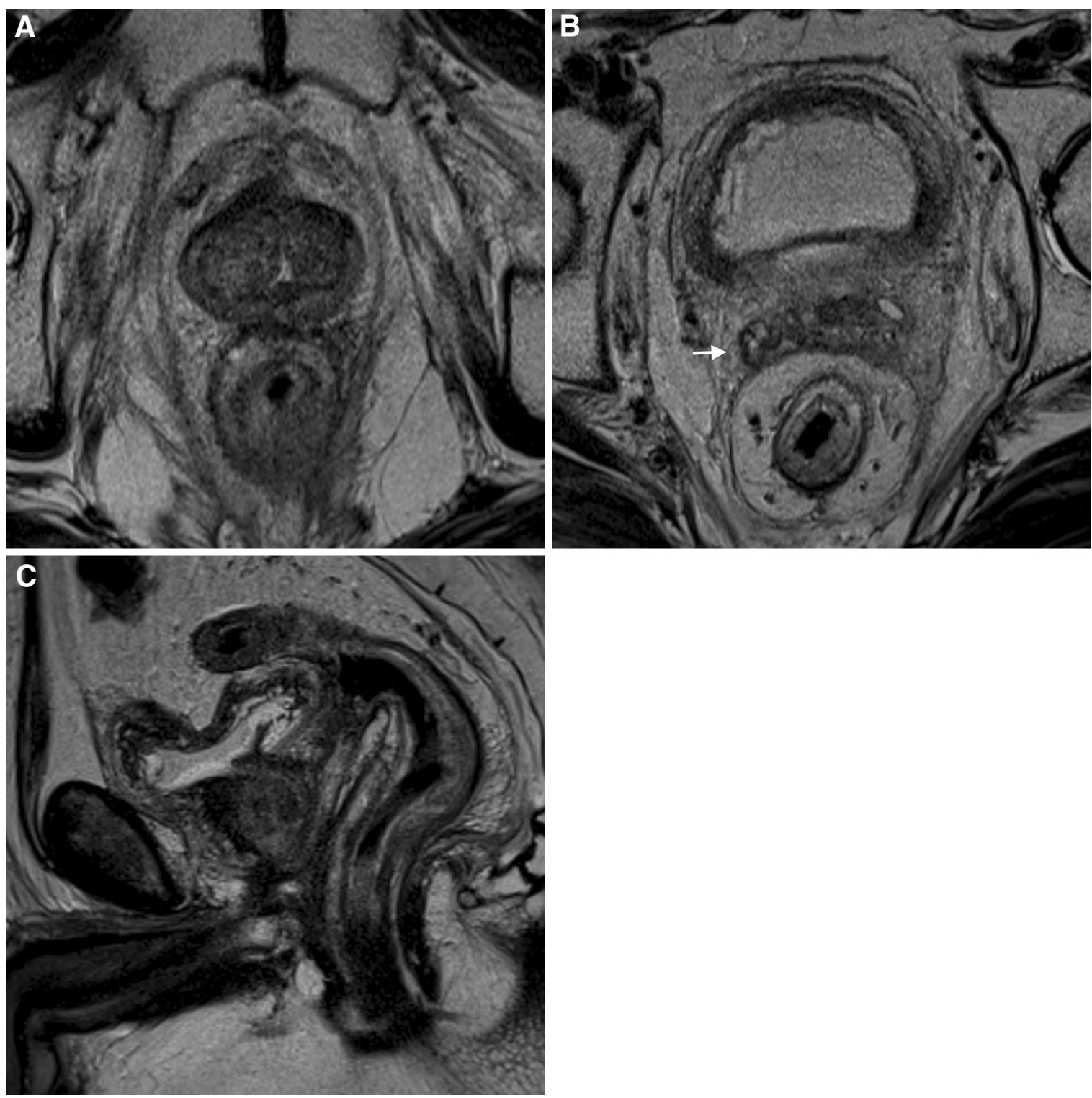

Fig. 12. Images in a 63-year-old man who underwent EBRT and $\mathrm{HT}$ due to a PCa (GS 8, with extracapsular extension). 5 years after starting treatment, PSA decreased from 12 to $0.25 \mathrm{ng} / \mathrm{mL}$. Axial (A, B) and sagittal (C) T2WI show diffuse signal hypointensity of the prostate gland and seminal vesicles (arrow), stranding of the surrounding fat planes, as well as diffuse thickening of the bladder and rectum walls, owing to radiation-induced cystitis and proctitis, respectively. 

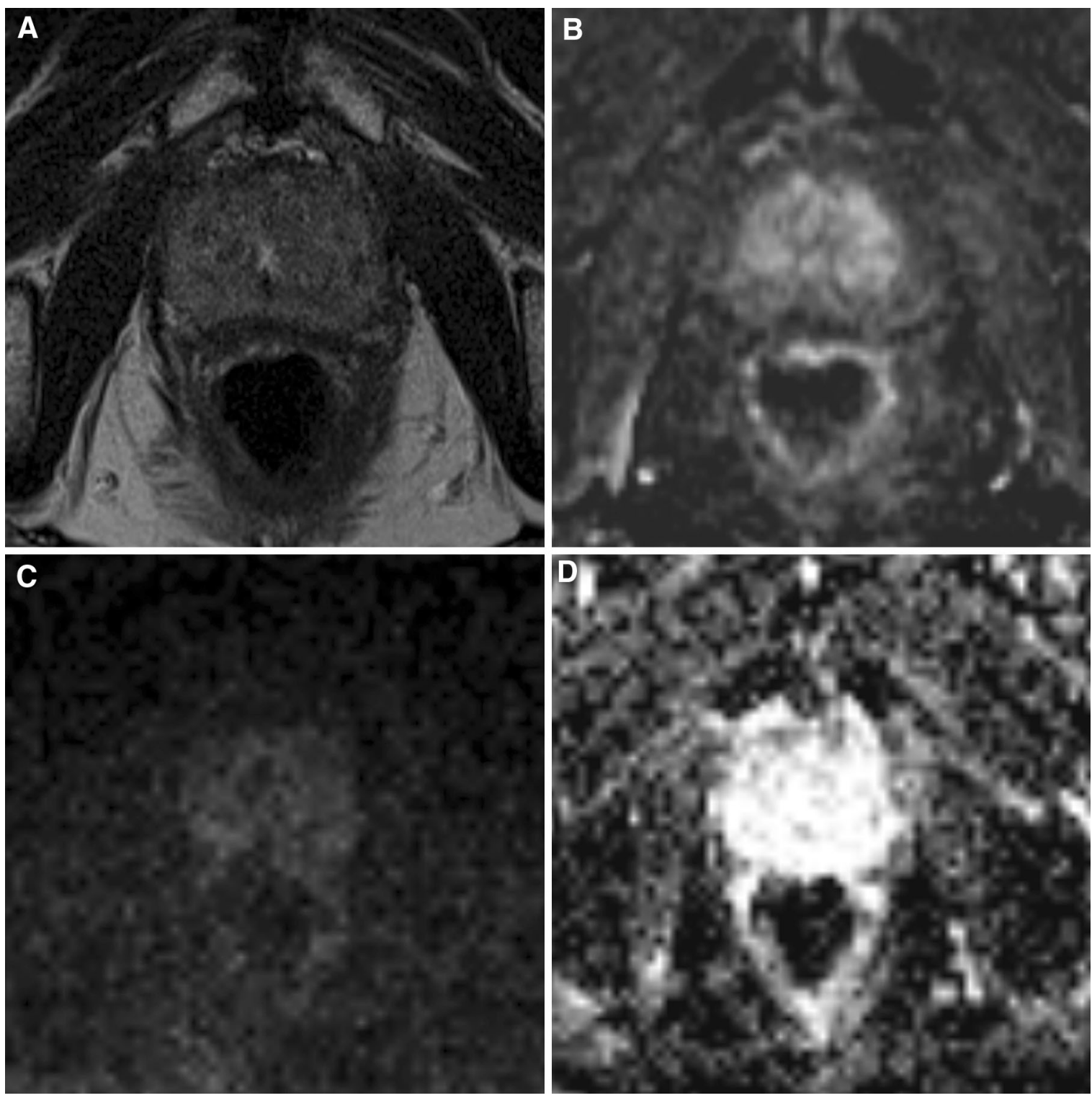

Fig. 13. Images in a 59-year-old man after EBRT and $\mathrm{HT}$ for PCa (GS 6 and initial PSA of $12.79 \mathrm{ng} / \mathrm{mL}$ ). 5 years later, PSA slightly increased from the immediate post-RT nadir to $1.42 \mathrm{ng} / \mathrm{mL}$. $\mathrm{mp}-\mathrm{MRI}$ and TRUS-guided biopsy were both negative for local recurrence. Axial T2WI (A) shows a dif-

fusely hypointense gland, with loss of the normal zonal anatomy. DCE images (B) show non-specific diffuse central enhancement. Images at b 1200 (C) show no significant restriction, with corresponding hypersignal on the ADC map (D). This is a non-suspicious shine-through effect. 

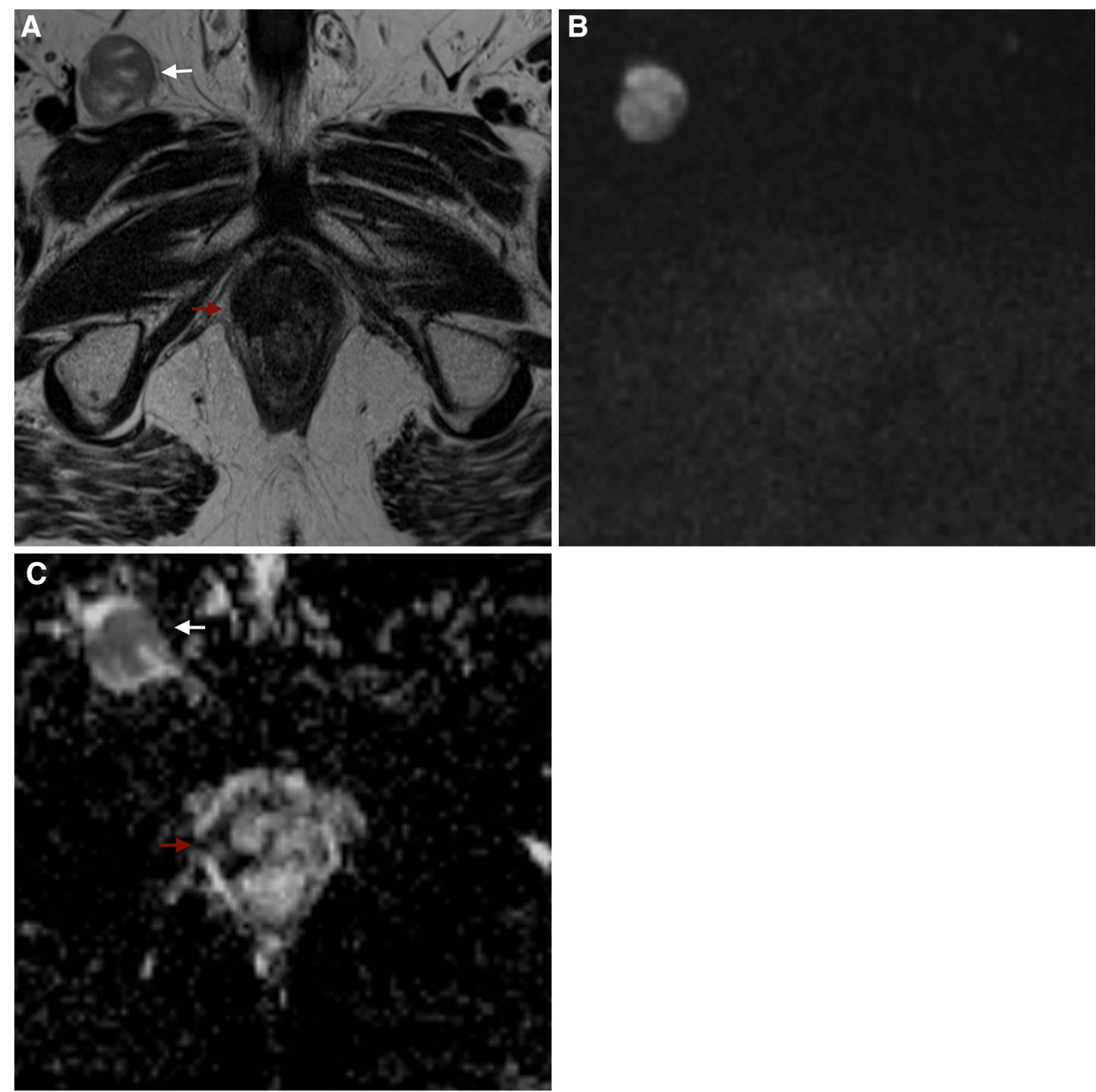

Fig. 14. Images in a 72-year-old man who underwent EBRT and complete hormonal blockage due to PCa (GS 9 and initial PSA of $33 \mathrm{ng} / \mathrm{mL}$ ). 3 years after EBRT, a significant BF was detected (PSA $19.1 \mathrm{ng} / \mathrm{mL}$ ) under HT. Axial T2WI (A) shows a small, diffusely hypointense prostate. At the right side, an

area of more pronounced hypointensity is found (red arrow), showing no restriction on DWI (B) and strong hyposignal on the ADC map (C), probably related to fibrotic tissue. However, a round, right inguinal node metastasis is seen, highly restrictive on DWI and dark on the ADC map (white arrows). 


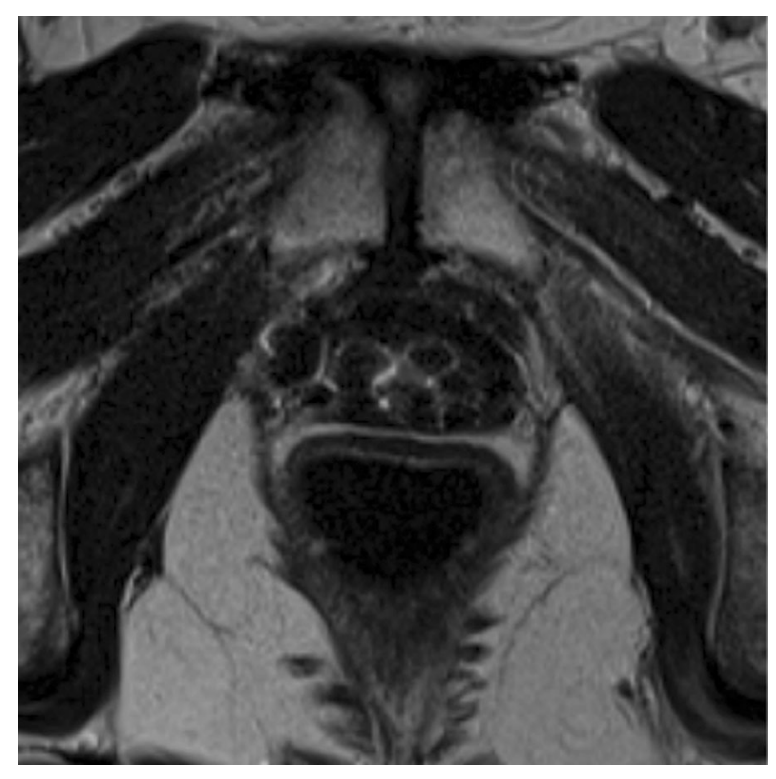

Fig. 15. Status post-BT. Axial T2WI shows exuberant artifacts that hamper prostatic parenchyma evaluation. 

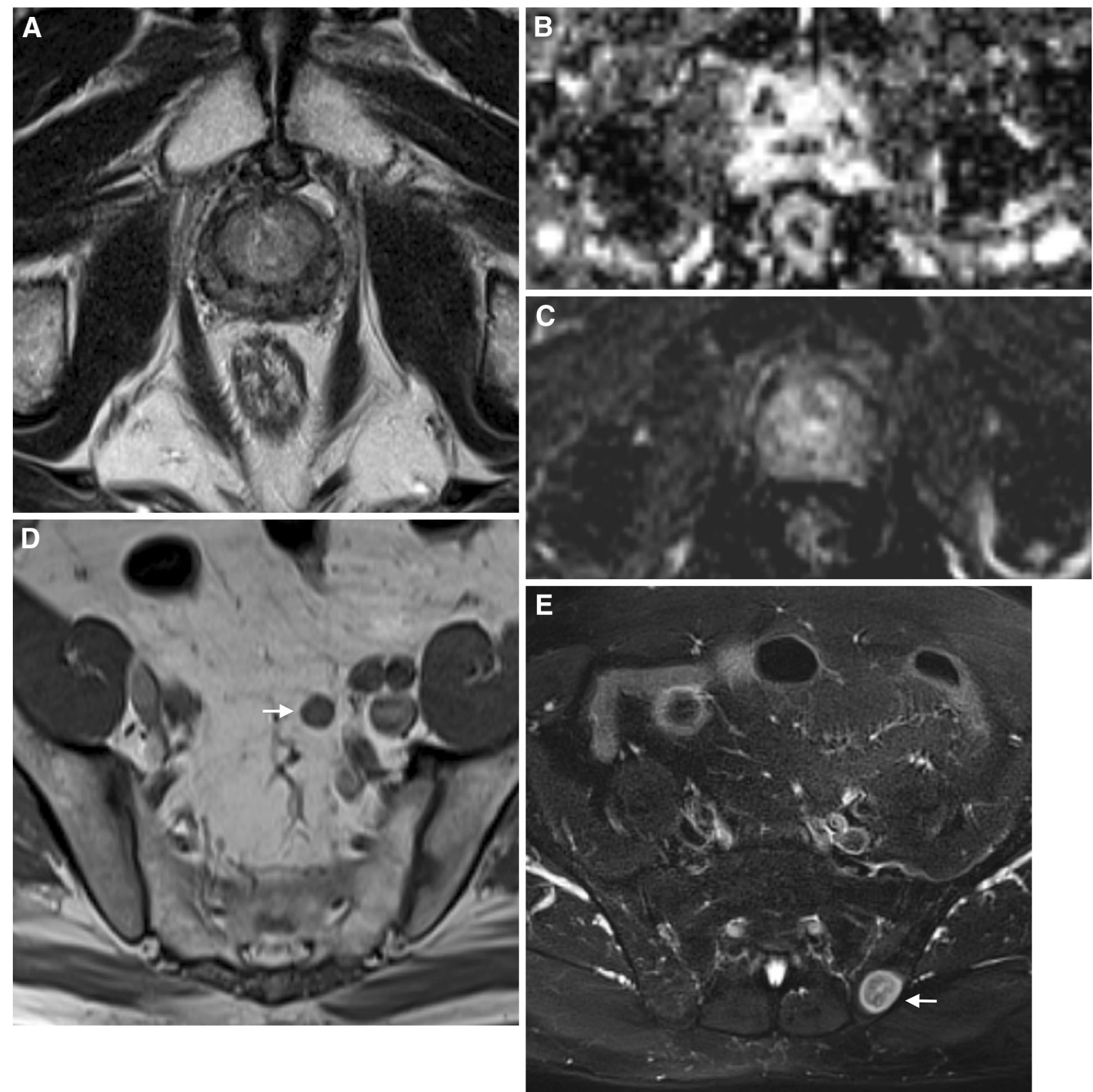

Fig. 16. Images in a 66-year-old man who underwent BT due to PCa (GS 7). PSA decreased from 5.63 to $1.97 \mathrm{ng} / \mathrm{mL}$ 1 month after treatment. 2 years later, BF was diagnosed (PSA $13.65 \mathrm{ng} / \mathrm{mL}$ ). Axial T2WI (A) shows a diffusely hypointense peripheral zone, with some dark spots corre- sponding to BT seeds, also seen on the ADC map (B). DCE images (C) show non-specific central enhancement. Axial T1WI (D) and T2WI FS (E) demonstrate a left internal iliac node metastasis and a left iliac bone metastasis, respectively (arrows). 

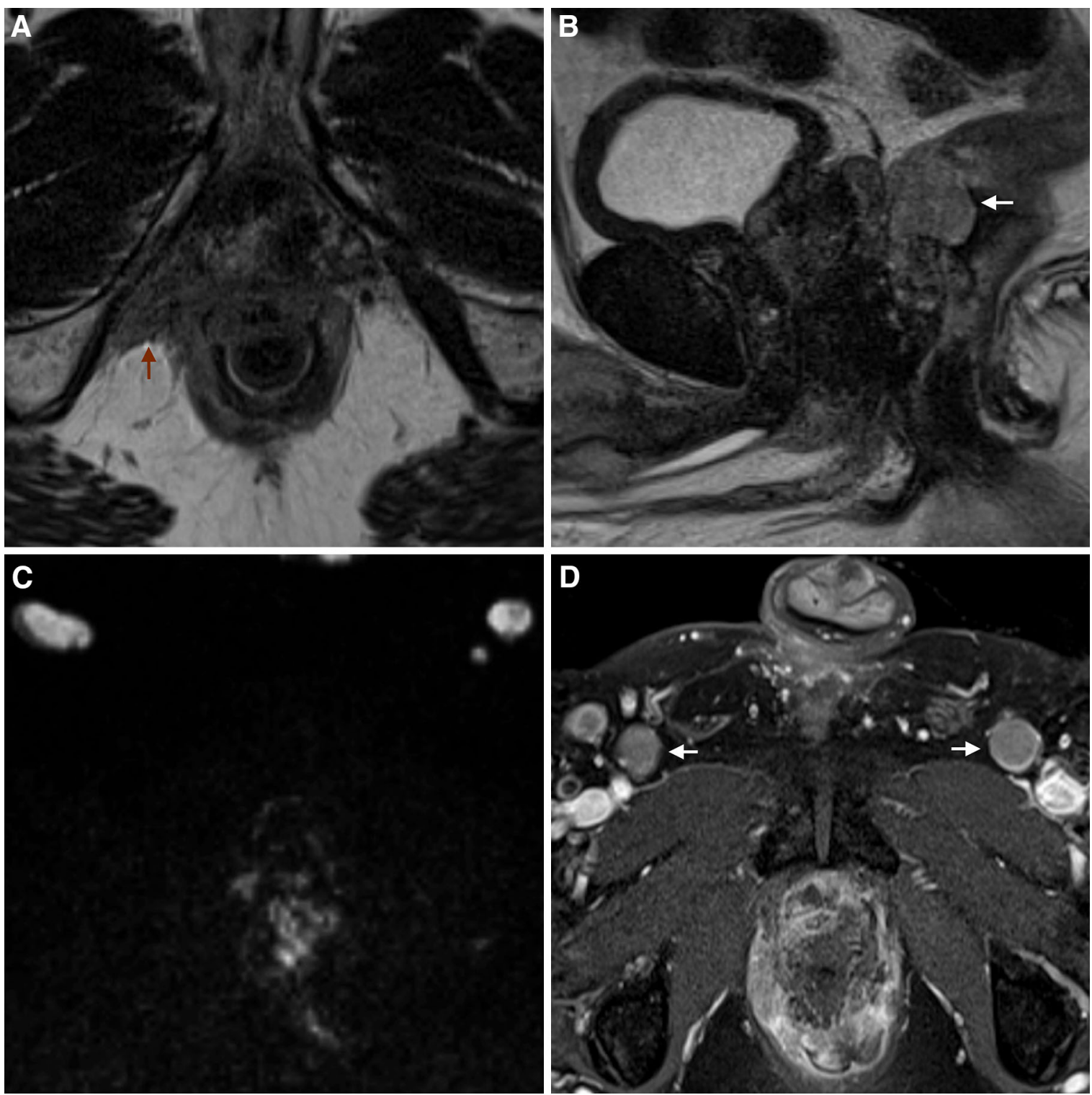

Fig. 17. Images in a 50-year-old man after $\mathrm{BT}$ due to a $\mathrm{PCa}$ (GS 7). 10 years after, BF was detected (PSA $6.2 \mathrm{ng} / \mathrm{mL}$ ). Axial (A) and sagittal (B) T2WI show an exuberant local recurrence, seen as a huge tumor with extracapsular extension (red arrow) and invasion of the seminal vesicles and

rectum (white arrow). Local tumor relapse shows strong restriction on DWI at b 1200 (C) and slightly peripheral enhancement on DCE images (D), probably due to necrosis. Bilateral, inguinal node metastases are also seen on both DWI and DCE images (arrows). 

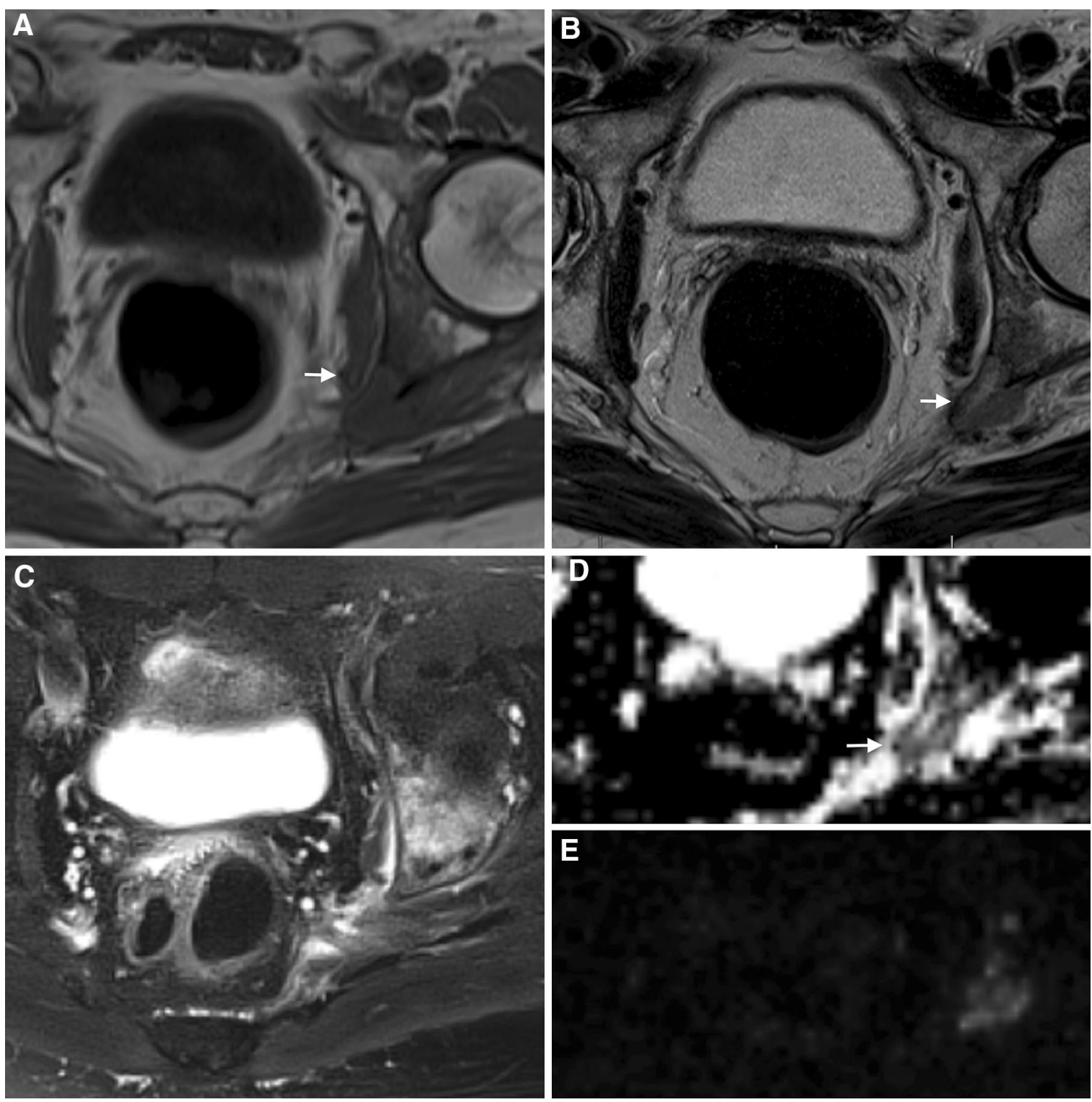

Fig. 18. Images in a 61-year-old man after BT. This patient had a PCa (GS 6) and a BF was detected 6 years after treatment (PSA $2.4 \mathrm{ng} / \mathrm{mL}$ ). Axial T1WI (A) and T2WI (B) show a pathologic fracture in the posterior column of the left acetabulum, associated with a soft tissue component and

cortical disruption (arrows). Edema of the surrounding muscles and acetabulum is seen on T2WI FS (C). Soft tissue component is, respectively, dark and bright on the ADC map (D) and DWI, denoting restriction (E). 

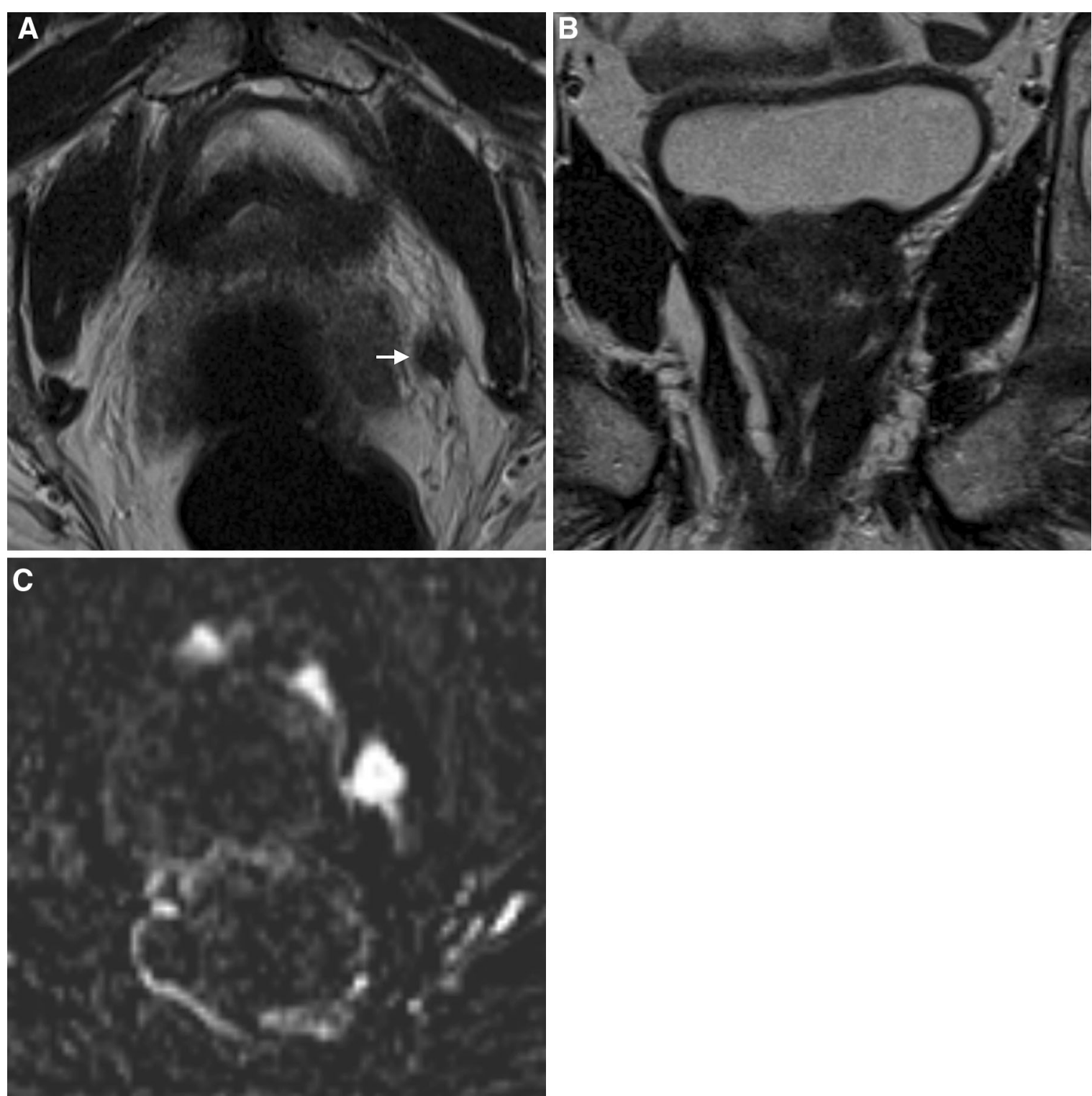

Fig. 19. Images in a 72-year-old man who underwent cryotherapy due to PCa (GS 7). 6 years later, BF was detected (PSA $1.27 \mathrm{ng} / \mathrm{mL}$ ) and patient started HT. Rectal gas artifacts impair axial T2WI $(\mathbf{A})$ reading, but a hypointense

nodule may be seen close to the left seminal vesicle (arrow). Coronal T2WI (B) shows a small, diffusely hypointense gland. DCE images (C) better depicts local recurrence, showing three enhanced nodules. 

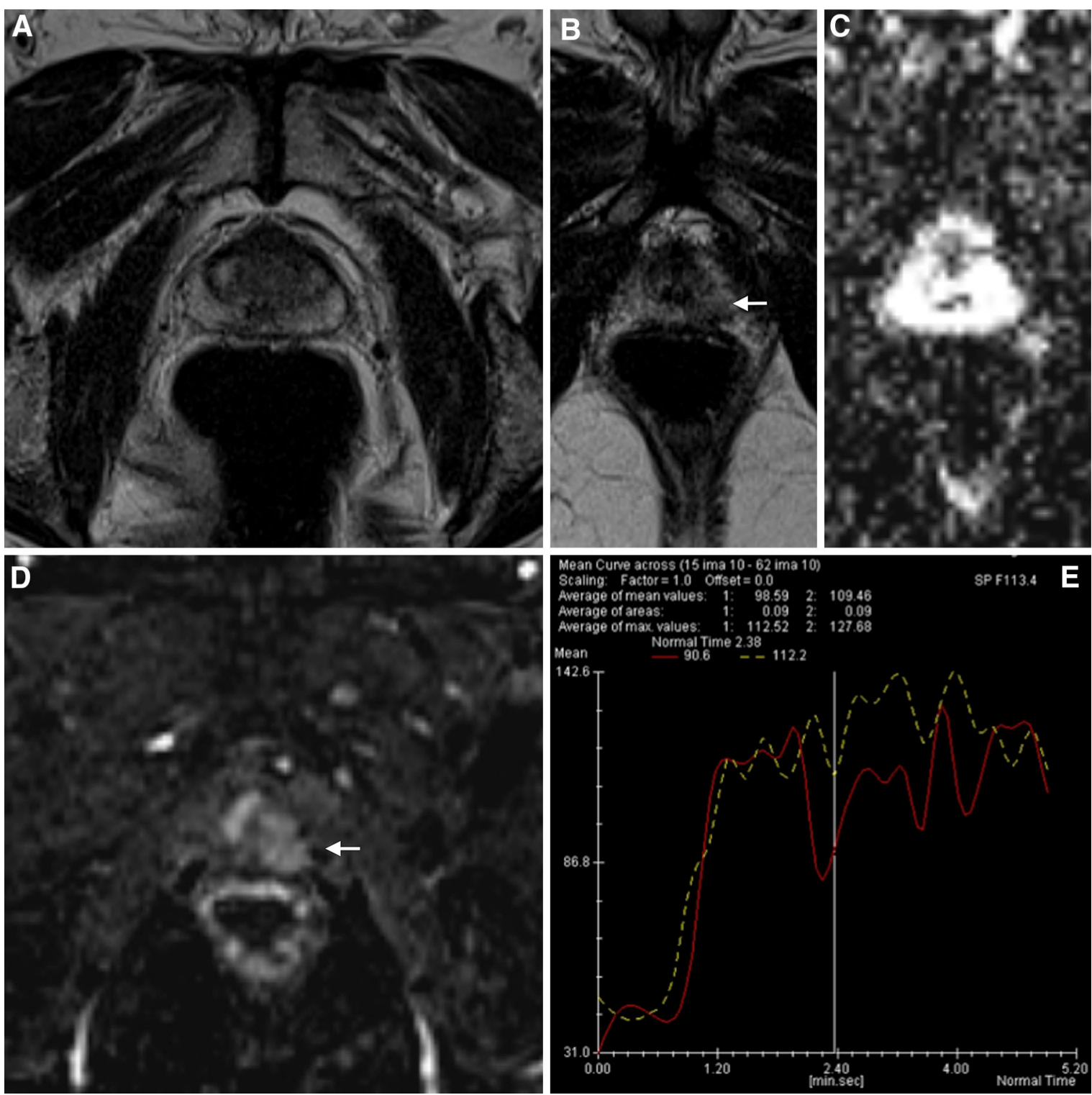

Fig. 20. Images in a 61-year-old man. This patient had a PCa (GS 7 and a initial PSA of $9.5 \mathrm{ng} / \mathrm{mL}$ ) and refused EBRT or RP. HT was started. After 10 years, PSA was $1.38 \mathrm{ng} / \mathrm{mL}$ and the patient remained asymptomatic. Axial T2WI (A, B) show a small prostate, with conserved zonal anatomy. In the left apex, a hypointense lesion is found (arrow), with corre-

sponding non-suspicious high signal on the ADC map (C). This lesion demonstrates progressive enhancement on DCE images (D), with type 1 curve (E), probably corresponding to a focal area of inflammation. No local tumor progression was found. 

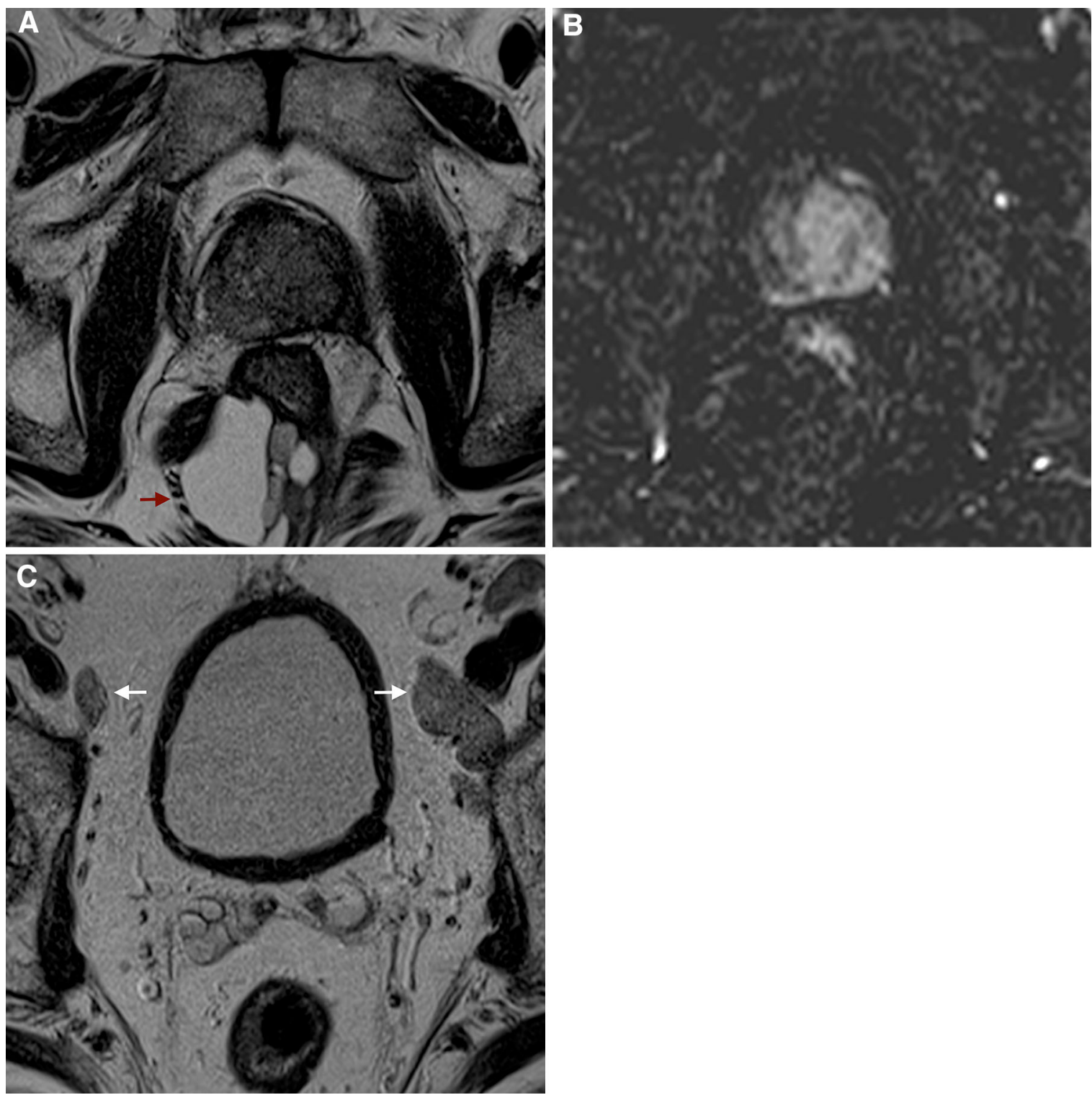

Fig. 21. Images in a 66-year-old man. This patient had a PCa (GS 7 and a initial PSA of $22 \mathrm{ng} / \mathrm{mL}$ ). HT was started and after 10 months PSA was $0.55 \mathrm{ng} / \mathrm{mL}$. HT was then interrupted and the patient remained asymptomatic. 1 year later, PSA increased to $9.68 \mathrm{ng} / \mathrm{mL}$. Axial T2WI (A) shows a diffusely hypointense, small prostate, with left spiculated contour

suggesting extracapsular extension. DCE images (B) demonstrate avid enhancement involving both left central and peripheral gland. Axial T2WI (C) also shows bilateral, external iliac lymph node metastases (arrows). A right perianal abscess is also depicted (red arrow). 


\section{Conclusion}

Once a post-treatment BF is detected, local or distant recurrence should be recognized. Several studies have already demonstrated the value of mp-MRI in the detection of post-RP and EBRT tumor relapse. The combination of morphological sequences with functional techniques like DCE-MRI and DWI has improved diagnostic accuracy levels and is now widely accepted and used.

Susceptibility magnetic artifacts after BT appear to significantly hamper tumor foci detection within the gland. However, in some non-artifact-hampered exams, mp-MRI might be useful to distinguish between clinically irrelevant PSA bounce and true BF. This issue remains controversial and surely implies further research. Moreover, other studies are also needed to validate the use of mp-MRI in the detection of recurrent PCa after less widespread therapies, like cryosurgery or HIFU.

Even in the assessment of distant metastases, MRI may be used. Despite bone scans and abdominopelvic CT being typically the first choices, both bone and lymph node metastases may be identified on MRI. Particularly in high-risk patients, an MRI protocol including T1WI and STIR sequences is already set as an alternative to bone scans.

\section{References}

1. Barentsz JO, Richenberg J, Clements R, et al. (2012) ESUR prostate MR guidelines 2012. Eur Radiol 22(4):746-757

2. Turkbey B, Albert PS, Kurdziel K, et al. (2009) Imaging localized prostate cancer: current approaches and new developments. AJR Am J Roentgenol 192(6):1471-1480

3. Choi YJ, Kim JK, Kim N, et al. (2007) Functional MR imaging of prostate cancer. Radiographics 27(1):63-75

4. Kirkham APS, Haslam P, Keanie JY, et al. (2013) Prostate MRI: who, when, and how? Report from a UK consensus meeting. Clin Radiol 68(10):1016-1023

5. Heidenreich A, Bellmunt J, Bolla M, et al. (2011) EAU guidelines on prostate cancer. Part 1: screening, diagnosis, and treatment of clinically localised disease. Eur Urol 59(1):61-71

6. Roach MR III, Hanks G, Thames H Jr, et al. (2006) Defining biochemical failure following radiotherapy with or without hormonal therapy in men with clinically localized prostate cancer: recommendations of the RTOG-ASTRO Phoenix Consensus Conference. Int J Radiat Oncol Biol Phys 65(4):965-974

7. Beresford MJ, Gillatt D, Benson RJ, et al. (2010) A systematic review of the role of imaging before salvage radiotherapy for postprostatectomy biochemical recurrence statement of search strategies used and sources of information. Clin Oncol 22(1):46-55

8. Rouvière O, Vitry T, Lyonnet D (2010) Imaging of prostate cancer local recurrences: why and how? Eur Radiol 20:1254-1266

9. Boorjian SA, Thompson RH, Tollefson MK, et al. (2011) Longterm risk of clinical progression after biochemical recurrence following radical prostatectomy: the impact of time from surgery to recurrence. Eur Urol 59(6):893-899

10. Mottet N, Bellmunt J, Bolla M, et al. (2011) EAU guidelines on prostate cancer. Part II: treatment of advanced, relapsing, and castration-resistant prostate cancer. Eur Urol 59(4):572-583

11. Brogsitter C, Zöphel K, Kotzerke J (2013) 18F-Choline, 11C-choline and $11 \mathrm{C}$-acetate $\mathrm{PET} / \mathrm{CT}$ : comparative analysis for imaging prostate cancer patients. Eur J Nucl Med Mol Imaging 40(Suppl):S18-S27

12. Lecouvet E, El J, Collette L, et al. (2012) Can whole-body magnetic resonance imaging with diffusion-weighted imaging replace Tc
$99 \mathrm{~m}$ bone scanning and computed tomography for single-step detection of metastases in patients with high-risk prostate cancer? Eur Urol 62:68-75

13. Beer AJ, Eiber M, Souvatzoglou M, et al. (2011) Radionuclide and hybrid imaging of recurrent prostate cancer. Lancet Oncol 12(2):181-191

14. Gomez P, Manoharan M, Kim SS, et al. (2004) Radionuclide bone scintigraphy in patients with biochemical recurrence after radical prostatectomy: when is it indicated? BJU Int 94:299-302

15. Gutzeit A, Doert A, Froehlich JM, et al. (2010) Comparison of diffusion-weighted whole body MRI and skeletal scintigraphy for the detection of bone metastases in patients with prostate or breast carcinoma. Skeletal Radiol 39:333-343

16. Fuccio C, Castellucci P, Schiavina R, et al. (2012) Role of 11Ccholine PET/CT in the re-staging of prostate cancer patients with biochemical relapse and negative results at bone scintigraphy. Eur J Radiol 81:893-896

17. Luboldt W, Kufer R, Blumstein N, et al. (2008) Prostate carcinoma: diffusion-weighted imaging as potential alternative to conventional $\mathrm{MR}$ and $11 \mathrm{C}$-choline $\mathrm{PET} / \mathrm{CT}$ for detection of bone metastases. Radiology 249(3):1017-1025

18. Eiber M, Holzapfel K, Ganter C, et al. (2011) Whole-body MRI including diffusion-weighted imaging (DWI) for patients with recurring prostate cancer: technical feasibility and assessment of lesion conspicuity in DWI. J Magn Reson Imaging 33:1160-1170

19. Liauw SL, Pitroda SP, Eggener SE, et al. (2013) Evaluation of the prostate bed for local recurrence after radical prostatectomy using endorectal magnetic resonance imaging. Int $\mathbf{J}$ Radiat Oncol Biol Phys 85(2):378-384

20. Joniau S, Van den Bergh L, Lerut E, et al. (2013) Mapping of pelvic lymph node metastases in prostate cancer. Eur Urol 63(3):450-458

21. Tewari A, Sooriakumaran P, Bloch D, et al. (2012) Positive surgical margin and perioperative complication rates of primary surgical treatments for prostate cancer: a systematic review and metaanalysis comparing retropubic, laparoscopic, and robotic prostatectomy. Eur Urol 62(1):1-15

22. Park BH, Jeon HG, Jeong BC, et al. (2014) Influence of magnetic resonance imaging in the decision to preserve or resect neurovascular bundles at robotic assisted laparoscopic radical prostatectomy. J Urol 192(1):82-88

23. Briganti A, Joniau S, Gontero P, et al. (2012) Identifying the best candidate for radical prostatectomy among patients with high-risk prostate cancer. Eur Urol 61:584-592

24. Joniau S, Hsu C-Y, Gontero P, et al. (2012) Radical prostatectomy in very high-risk localized prostate cancer: long-term outcomes and outcome predictors. Scand J Urol Nephrol 46(3):164-171

25. Roethke MC, Lichy MP, Kniess M, et al. (2013) Accuracy of preoperative endorectal MRI in predicting extracapsular extension and influence on neurovascular bundle sparing in radical prostatectomy. World J Urol 31(5):1111-1116

26. Panebianco V, Salciccia S, Cattarino S, et al. (2012) Use of multiparametric MR with neurovascular bundle evaluation to optimize the oncological and functional management of patients considered for nerve-sparing radical prostatectomy. J Sex Med 9:2157-2166

27. Pound CR, Partin AW, Eisenberger MA, et al. (1999) Natural history of progression after PSA elevation following radical prostatectomy. JAMA 281(17):1591-1597

28. Amling CL, Bergstralh EJ, Blute ML, et al. (2001) Defining prostate specific antigen progression after radical prostatectomy: what is the most appropriate cut point? J Urol 165(April):1146-1151

29. Cirillo S, Petracchini M, Scotti L, et al. (2009) Endorectal magnetic resonance imaging at 1.5 Tesla to assess local recurrence following radical prostatectomy using $\mathrm{T} 2$-weighted and contrast-enhanced imaging. Eur Radiol 19:761-769

30. Sciarra A, Panebianco V, Salciccia S, et al. (2008) Role of dynamic contrast-enhanced magnetic resonance (MR) imaging and proton MR spectroscopic imaging in the detection of local recurrence after radical prostatectomy for prostate cancer. Eur Urol 54:589-600

31. Sella T, Schwartz LH, Swindle PW, et al. (2004) Suspected local recurrence after radical prostatectomy: endorectal coil MR imaging. Radiology 231:379-385

32. Casciani E, Polettini E, Carmenini E, et al. (2008) Endorectal and dynamic contrast-enhanced MRI for detection of local recurrence after radical prostatectomy. Acta Radiol 190(5):1187-1192 
33. Nilsson S, Norlén BJ, Widmark A (2004) A systematic overview of radiation therapy effects in prostate cancer. Acta Oncol (Madr) 43(4):316-381

34. Haider M, Chung P, Sweet J, et al. (2008) Dynamic contrast-enhanced magnetic resonance imaging for localization of recurrent prostate cancer after external beam radiotherapy. Int J Radiat Oncol Biol Phys 70(2):425-430

35. Kim C, Park B, Lee H (2009) Prediction of locally recurrent prostate cancer after radiation therapy: incremental value of $3 \mathrm{~T}$ diffusion-weighted MRI. J Magn Reson Imaging 29(2):391-397

36. Morgan V, Riches S, Giles S, et al. (2012) Diffusion-weighted MRI for locally recurrent prostate cancer after external beam radiotherapy. AJR Am J Roentgenol 198(3):596-602

37. Donati OF, Il Jung S, Vargas HA, et al. (2013) Multiparametric prostate MR imaging with T2-weighted, diffusion-weighted, and dynamic contrast-enhanced sequences: are all pulse sequences necessary to detect locally recurrent prostate cancer after radiation therapy? Radiology 268(2):440-450

38. Arumainayagam N, Kumaar S, Ahmed HU, et al. (2010) Accuracy of multiparametric magnetic resonance imaging in detecting recurrent prostate cancer after radiotherapy. BJU Int 106:991-997

39. Akin O, Gultekin DH, Vargas HA, et al. (2011) Incremental value of diffusion weighted and dynamic contrast enhanced MRI in the detection of locally recurrent prostate cancer after radiation treatment : preliminary results. Eur Radiol 21:1970-1978

40. Pucar D, Hricak H, Kuroiwa K, et al. (2005) Prostate cancer: correlation of MR imaging and MR spectroscopy with pathologic findings after radiation therapy - initial experience. Radiology 236:545-553
41. Ash D, Flynn A, Battermann J, et al. (2000) ESTRO/EAU/ EORTC recommendations on permanent seed implantation for localized prostate cancer. Radiother Oncol 57:315-321

42. Han K, Belldegrun A (2004) Third-generation cryosurgery for primary and recurrent prostate cancer. BJU Int 93:14-18

43. Fahmy W, Bissada N (2003) Cryosurgery for prostate cancer. Arch Androl 49:397-407

44. Rees J, Patel B, Macdonagh R, et al. (2004) Cryosurgery for prostate cancer. BJU Int 93:710-714

45. Aus G (2006) Current status of HIFU and cryotherapy in prostate cancer - a review. Eur Urol 50(5):927-934

46. Parivar F, Hricak H, Shinohara K, et al. (1996) Detection of locally recurrent prostate cancer after cryosurgery: evaluation by transrectal ultrasound, magnetic resonance imaging, and three-dimensional proton magnetic resonance spectroscopy. Urology 48(4):594-599

47. Sharifi N, Gulley JL, Dahut WL (2005) Androgen deprivation therapy for prostate cancer. JAMA 294(2):238-244

48. Hussain M, Tangen C, Higano C, et al. (2006) absolute prostatespecific antigen value after androgen deprivation is a strong independent predictor of survival in new metastatic prostate cancer: data from Southwest Oncology Group Trial 9346 (INT-0162). J Clin Oncol 24(24):3984-3990

49. Stewart A, Scher H, Chen M, et al. (2005) Prostate-specific antigen nadir and cancer-specific mortality following hormonal therapy for prostate-specific antigen failure. J Clin Oncol 23(27):6556-6560 